\title{
MORPHOLOGY AND DIAGNOSTIC POTENTIAL OF THE IONOSPHERIC ALFVÉN RESONATOR
}

\author{
A.S. Potapov \\ Institute of Solar-Terrestrial Physics SB RAS, \\ Irkutsk, Russia,potapov@iszf.irk.ru
}

\section{T.N. Polyushkina}

Institute of Solar-Terrestrial Physics SB RAS, Irkutsk, Russia,tnp@iszf.irk.ru

\author{
B. Tsegmed \\ Institute of Astronomy and Geophysics MAS, \\ Ulaanbaator, Mongolia,tseg@iag.ac.mn
}

\begin{abstract}
The layering of the ionosphere leads to the formation of resonators and waveguides of various kinds. One of the most well-known is the ionospheric Alfvén resonator (IAR) whose radiation can be observed both on Earth's surface and in space in the form of a fan-shaped set of discrete spectral bands (DSB), the frequency of which changes smoothly during the day. The bands are formed by Alfvén waves trapped between the lower part of the ionosphere and the altitude profile bending of Alfvén velocity in the transition region between the ionosphere and the magnetosphere. Thus, IAR is one of the important mechanisms of the ionosphere-magnetosphere interaction. The emission frequency lies in the range from tenths of hertz to about 8 $\mathrm{Hz}$ - the frequency of the first harmonic of the Schumann resonance. The review describes in detail the morphology of the phenomenon. It is emphasized that the IAR emission is a permanent phenomenon; the probability of observing it is primarily determined by the sensitivity of the equipment and the absence of interference of natural and artificial origin. The daily duration of the DSB observation almost completely depends on the illumination conditions of the lower ionosphere: the bands are clearly visible only when the D layer is shaded. Numerous theoretical IAR models have been systematized. All of them are based on the analysis of the excitation and propagation of Alfvén waves in
\end{abstract}

inhomogeneous ionospheric plasma and differ mainly in sources of oscillation generation and methods of accounting for various factors such as interaction of wave modes, dipole geometry of the magnetic field, frequency dispersion of waves. Predicted by all models of the cavity and repeatedly confirmed experimentally, the close relationship between DSB frequency variations and critical frequency $f_{\mathrm{o}} \mathrm{F} 2$ variations serves as the basis for searching ways of determining in real time the electron density of the ionosphere from IAR emission frequency measurements. It is also possible to estimate the profile of the ion composition over the ionosphere from the data on the IAR emission frequency structure. The review also focuses on other results from a wide range of IAR studies, specifically on the results that revealed the influence of the interplanetary magnetic field orientation on oscillations of the resonator, and on the facts of the influence of seismic disturbances on IAR.

Keywords: spectral bands, ultra low frequency emission, resonator, standing Alfvén waves, harmonic structure, wave modes, electron density, diagnostics.

\section{CONTENT}

Introduction

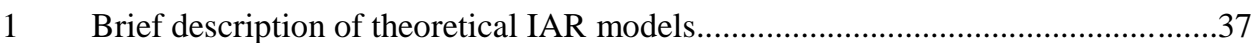

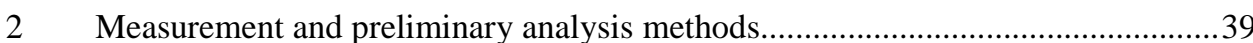

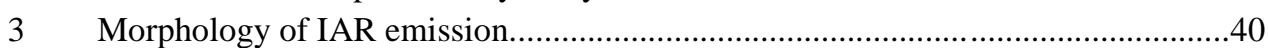

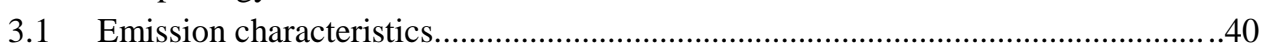

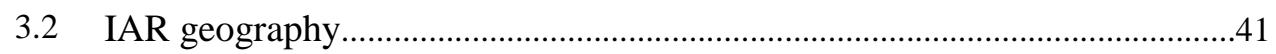

3.3 IAR emission dependence on solar cycle, season, and magnetic disturbance.

Diurnal variation in probability of observing DSB ..............................................42

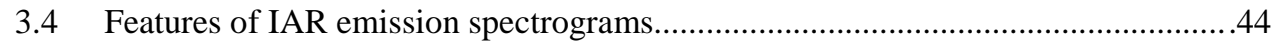

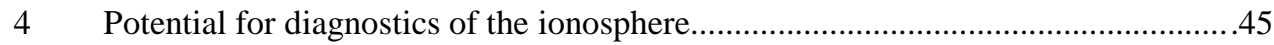

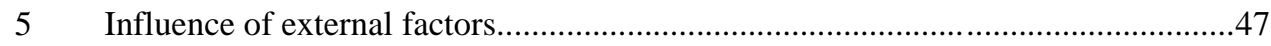

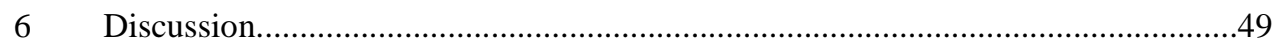

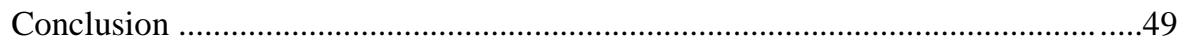




\section{INTRODUCTION}

One of the important features of the ionospheric magnetic plasma structure is the presence of the resonant cavity for Alfvén waves between the base of the ionosphere and the region of transition to the magnetosphere. Above, the resonator is bounded by the profile bending of Alfvén velocity $c_{\mathrm{A}}=B / \sqrt{4 \pi \rho}$ ( $B$ is the magnetic field, $\rho$ is the plasma density) at a height from $\sim 1000$ to $6000 \mathrm{~km}$. Wave reflection there occurs as a result of violation of geometrical optics conditions; therefore, the height of the upper boundary for each frequency is slightly different (a specific value of height depends on conditions of the magnetosphere-ionosphere system). Of particular importance is the ion composition; this condition can, in principle, be used to gain information about vertical profiles of ion content (see Section 4).

The lower boundary of the cavity coincides with the E-region of the ionosphere at a height of 100 to $150 \mathrm{~km}$. Reflection from it occurs either due to the high transversal conductivity of the E layer [Lysak, 1991] or, as from the upper boundary, due to violation of geometrical optics conditions [Belyaev, 1989; Belyaev et al., 1990] at a sharp Alfvén velocity gradient appearing below the ionization maximum in the F2 layer of the ionosphere. In fact, both variants may be realized depending on specific conditions; however, the former is likely to be preferable [Guglielmi et al., 2021]. In this case, the perfect conductivity of Earth's surface plays a significant role. The frequency of Alfvén waves trapped by the cavity lies in the upper part of the band of ultra low frequency (ULF) oscillations - below 8-10 Hz.

S.V. Polyakov was the first who paid attention to the possible existence of the resonant cavity [Polyakov, 1976], naming it the ionospheric Alfvén resonator (IAR); later on, this term became generally accepted. Due to dedicated experimental searches carried out by NIRFI researchers, a decade later P.P. Belyaev [Belyaev et al., 1987] managed to detect the multiband ULF emission that in its features completely coincided with the expected features of the IAR emission. In a daily spectrogram, it has a characteristic form of discrete spectral bands (DSB) whose frequency and the distance between them (frequency scale) increase from noon to midnight and decrease in the morning.

Later on, IAR has been extensively studied by many Russian and foreign researchers. The main contribution to the first phase of the research was made by [Trakhtengerts, Feldstein, 1991; Lysak, 1991; Belyaev et al., 1997]. Afterwards, in the literature there were a number of publications proposing theoretical IAR models (see, e.g., the review [Lysak, Yoshikawa, 2006] and references therein) and analyzing DSB observations in various regions [Belyaev et al., 1999; Yahnin et al., 2003; Pokhotelov et al., 2003; Molchanov et al., 2004; Bösinger et al., 2004; Potapov et al., 2014, 2017; Baru et al., 2016].

At present, it is clear that the ionospheric Alfvén resonator is an integral part of the entire ionosphericmagnetospheric structure. It plays a significant role in energy exchange and interaction between these two regions of near-Earth space. In our review, we address various aspects of the IAR problem, critically describing earlier results and drawing attention to unresolved research problems. We show that IAR, like the ionosphere itself, is a permanent phenomenon existing on a global scale regardless of solar and magnetic activity. Meanwhile, resonator emission characteristics vary in time and space, following changes in the state of the ionosphere in a given region. Diurnal and seasonal variations in ionospheric parameters, as well as its sporadic disturbances, produce an emission frequency and amplitude modulation effect.

The purpose of this review is to analyze the current state of the problem and to discuss still unresolved issues and tasks of future IAR research. Section 1 briefly reviews fundamental theoretical models of the resonator and proposed mechanisms of its excitation. Section 2 describes methods of observation and preliminary analysis of the IAR emission; Section 3 depicts its morphological characteristics. Section 4 explores the possibilities and difficulties of using measurements of the resonator emission for diagnosing the state of the ionosphere and variations in its parameters. Then, we delve into the influence of external factors on the amplitude and frequency mode of the resonator (Section 5). The final two sections deal with general aspects of the problem and formulate conclusions.

\section{BRIEF DESCRIPTION OF THEORETICAL IAR MODELS}

In the literature, various versions of the IAR emission generation model have been proposed [Trakhtengertz, Feldstein, 1987; Lysak, 1991; Belyaev et al., 1989, Polyakov, Rapoport, 1981; Demekhov et al., 2000; Pokhotelov et al., 2000; Lysak, Yoshikawa, 2006; Fedorov et al., 2016a, c]. They all are based on the idea of capturing Alfvén waves in the ionosphere between its lower part and the region of transition from the ionosphere to the magnetosphere, where geometrical optics conditions are violated. Somewhat aside from the general direction is the group of works (see, e.g., [Schekotov et al., 2011]) that attribute the cause of most DSB events not to the resonator emission but to the spectral representation of so-called paired pulses, the first of which is the lightning discharge, and the second results from the reflection of the first one from the upper boundary of the ionosphere. In any case, the general analysis method is to solve the dispersion equation for electromagnetic waves in ionospheric plasma with regard to boundary conditions. We do not give details of the calculations, which can be found in the above papers; instead, we present the main conclusions drawn from analytical and numerical calculations.

In the simplest model proposed in [Polyakov, Rapoport, 1981], the frequency of the $n$th harmonic of the resonator is equal to

$$
f_{n}=\frac{c_{\mathrm{A}}}{2 L}(n+\Phi),
$$

where $L$ is the length of the resonant cavity along a field 
line; $c_{\mathrm{A}}$ is the Alfven velocity under the assumption that the cavity is homogeneous; $\Phi$ is the phase factor depending on conditions of wave reflection from the lower boundary of the resonator. More detailed relations of IAR frequencies with the F2-region critical frequency of the ionosphere and the total electron content are given in [Fedorov et al., 2016c]. The wave reflection coefficient depends on the integral Pedersen plasma conductivity $\Sigma_{\mathrm{p}}$ in the lower ionosphere at a height of $\sim 100 \mathrm{~km}$ (see, e.g., [Belyaev et al., 1990]):

$$
R_{l}=\frac{1-4 \pi \Sigma_{\mathrm{p}} c_{\mathrm{A}} / c^{2}}{1+4 \pi \Sigma_{\mathrm{p}} c_{\mathrm{A}} / c^{2}},
$$

and the phase factor shows how the wave phase changes during reflection. It is equal to a fraction of a quarter wave length, which is added to an integer of half-waves in setting the mode of standing Alfvén waves required for resonance. This means that depending on the $\Phi$ value at the lower boundary a node or antinode of electric field of the wave trapped in the resonator is formed [Lysak, 1991; Hebden et al., 2005]. It is believed that during the daytime when the lower ionosphere is sunlit the solar ultraviolet radiation provides a high intensity of ion formation and hence an increase in conductivity. Under these conditions at the lower boundary of the resonator, a wave field node is formed for all harmonics. On the contrary, during the nighttime under minimum ionospheric conductivity, the phase shift at the lower boundary leads to the formation of a wave field antinode therein (Figure 1). Furthermore, the lower ionosphere's plasma conductivity changing under the effect of illumination variations produces daily dependence of the resonator Q factor [Polyakov, Rapoport, 1981; Nosé et al., 2017].

In turn, the depth and form of such modulation appear to depend on the season and the latitude of observation site. At low latitudes, the $\mathrm{Q}$ factor varies very sharply during the passage of the terminator, but weakly depends on the season [Nosé et al., 2017]. At middle and especially at high latitudes, the seasonal dependence

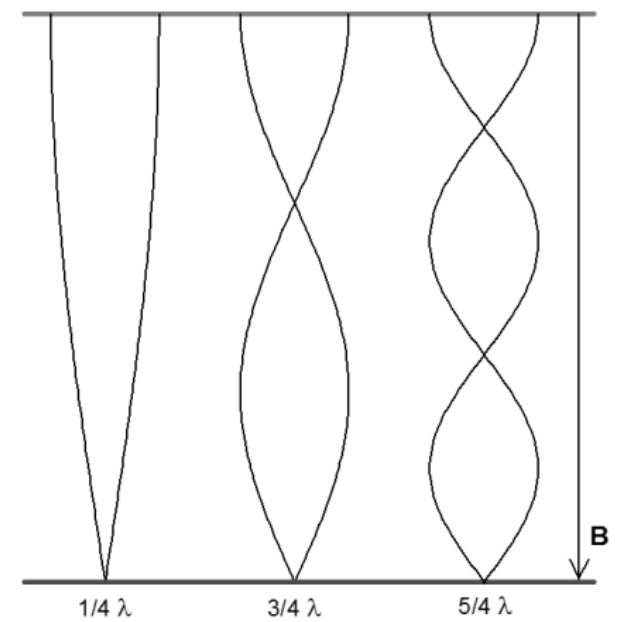

is high and manifests itself in the fact that in winter the $\mathrm{Q}$ factor is less dependent on local time than in summer [Yahnin et al., 2003].

The upper boundary of the resonator, according to various sources, is formed either by the maximum of the Alfvén velocity at an altitude of one to several thousand kilometers [Lysak, 1991], or simply by the bending of the velocity profile at the same height [Polyakov, Rapoport, 1981]. Both lead to violation of the conditions of geometrical optics in this area and partial reflection of wave energy. Conditions of wave reflection from the upper boundary can hardly be affected by diurnal and seasonal variations, but it is deemed that the reflection coefficient therein may depend on magnetic fieldand Sun-induced disturbances in the magnetosphere [Belyaev et al., 1997].

Despite the simplicity of the model that yields Formula (1), the relation between resonant frequencies of IAR and ionospheric parameters is quite convincingly confirmed by measurements. The closest relationship is observed between variations in the DSB frequency scale and variations in the electron density at the F2-layer peak, which strictly defines the critical frequency $f_{\mathrm{o}} \mathrm{F} 2$ of ionospheric sounding. We will return to this issue below.

The simplest model of uniform resonant cavity was further developed using both analytical and numerical methods. So, Lysak [2004] presented a numerical model in the form of a radially stratified ionosphere, which took into account, along with layering, slope of dipole geomagnetic field lines. In [Lysak, Yoshikawa, 2006; Lysak et al., 2013], this model was extended by consideration of the realistic vertical profile of ionospheric conductivity. All the versions of calculations made allowance for the interaction of Alfvén waves trapped by the resonator with magnetosonic waves propagating along Earth in the ionospheric waveguide at the level of the F2 layer as well as with waves excited in the magnetospheric Alfvén resonator (field-line resonator). They also took into account the influence of field-aligned currents at high latitudes.

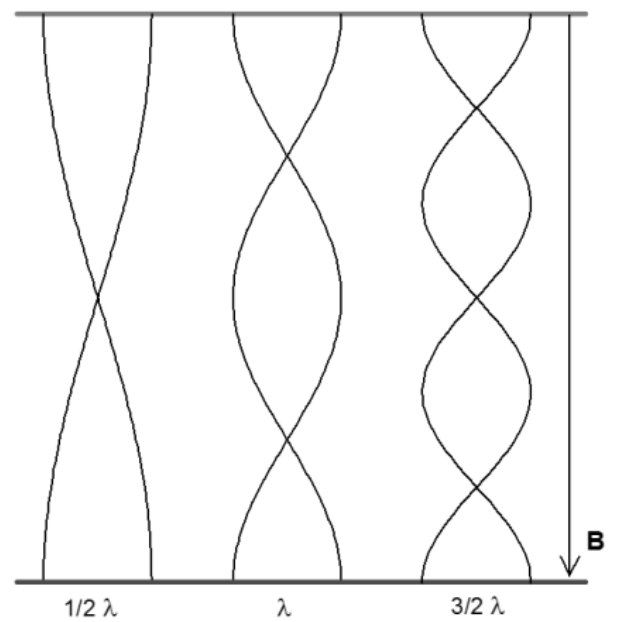

Figure 1. Schematic diagram illustrating the configuration of a perpendicular electric field in a standing Alfvén wave for the first three eigenmodes captured in IAR in the case of high (left) and low (right) ionospheric conductivity. Bottom horizontal lines indicate the lower ionosphere; top ones, the upper IAR boundary in the region of transition to the magnetosphere [Hebden et al., 2005]. 
The papers [Sciffer, Waters, 2002; Sciffer et al., 2005] discuss the role of Hall conductivity in the E layer for ground-based IAR emission observation. It has been shown that in contrast to earlier findings, with inclined field lines of the external magnetic field a wave can penetrate to Earth through the ionosphere even at zero Hall conductivity.

Lysak et al. [2013] exemplifies a numerical calculation illustrating the IAR effect on the mode of Pc1 geomagnetic pulsations with a $1-2 \mathrm{~Hz}$ frequency. The Pc1 series last longer when their frequency coincides with the frequency of one of the IAR harmonics; the Pc1 carrier frequency following changes in the resonator emission frequency. The authors explain this effect by the fact that Pc1 waves are trapped by the resonator and borrow its energy. However, this explanation is not unique. The fact is that at the IAR harmonics the socalled transparency windows for emissions from the magnetosphere are formed. On Earth, therefore, there are mainly those Pc1 series whose frequency coincides with one of the IAR resonant frequencies. This is reliably supported by experimental facts indicating the appearance of Pcl packets generally near the IAR emission harmonics and correlated with them in frequency [Prikner et al., 2004; Dovbnya et al., 2019a].

Much attention has been given in the literature to the search for possible sources - the drivers that excite IAR oscillations. The papers [Trakhtengertz, Feldstein, 1987; Lysak, 1991; Pokhotelov et al., 2001] proposed a hypothesis about the so-called feedback instability as a wave energy source in the IAR cavity. The point is that the field-aligned current associated with Alfvén waves trapped by the resonator can cause precipitation of energetic electrons, stimulating additional ionization in the ionosphere and modulating ionospheric conductivity. Such a feedback for certain relationships between wave characteristics and reflection power of the ionosphere can produce instability feeding the waves captured by the resonator. Trakhtengertz, Feldstein [1987] also included small-scale magnetic convection irregularities and turbulent heat of ionospheric plasma in the feedback chain. Nonetheless, this mechanism can work at high latitudes, but is unlikely at middle and low latitudes, where the IAR emission occurs equally as often as in the auroral and sub-auroral zones. Moreover, the feedback instability leads to excitation of waves with large wave numbers. These waves do not penetrate to Earth's surface. First studies on IAR therefore proposed another mechanism - excitation of the resonator due to thunderstorm activity [Belyaev et al., 1989] — both global and local. This mechanism is detailed in [Surkov et al., 2004, 2006; Fedorov et al., 2016b]. Lightning discharge was simulated as an electric dipole emission. While the discharge current increases for microseconds, its attenuation is exponential with a time scale of a tenth of a second. Such a rapidly increasing and slowly fading process has an almost flat spectrum at frequencies lower than the reverse attenuation time, i.e. of the order of 10 $\mathrm{Hz}$ in this case, which fits into the IAR frequency range. Another possible energy source for driving IAR oscillations may be neutral wind fluctuations causing variable ionospheric currents in the E layer [Molchanov et al., 2004; Surkov et al., 2004]. These currents can emit Alfvén and fast magnetosonic waves. The former penetrate into the upper ionosphere and the magnetosphere, and can be trapped by IAR. The latter propagate along the ionospheric waveguide and thus transfer energy far away from the point of generation, where they can transform into Alfvén waves and feed the resonator therein.

\section{MEASUREMENT AND PRELIMINARY ANALYSIS METHODS}

Figure 2 gives a typical example of daily spectrogram of resonator emission. Discrete spectral bands reflect the harmonic structure of the emission. The emission range is from tenths of a hertz to $\sim 8 \mathrm{~Hz}$ - the frequency of the first harmonic of the Schumann resonance. The emission amplitude is small - it does not exceed a few pikotesla. In fact, we see the noise whose intensity is modulated by the resonator. Frequencies close to the IAR resonant frequencies stand out from the continuous background noise spectrum. Unlike Schumann resonances whose first harmonic is shown as a horizontal line at the top of the spectrogram (Figure 2), the frequency of each IAR harmonic varies continuously during the day, passing two-three octaves. The matter is that Schumann resonances occur in the global spherical resonator Earth-ionosphere whose parameters do not change with time (eigenfrequency changes usually do not exceed $10 \%$ ). In contrast, the IAR resonant frequencies are determined mainly by the ionospheric electron density greatly varying during the day in response to variations in the solar ultraviolet radiation.

The small amplitude of IAR emission requires highsensitive equipment and the absence of external interference of artificial or natural origin to measure it. The most commonly used device for recording ULF emissions of this type is an induction magnetometer. It consists of a multiturn coil with the core of an alloy having high magnetic permeability, a preamplifier, a set of filters, an analog to digital converter (ADC), and a digital storage. For precise timing, the device should be equipped with a receiver of signals from the global navigation satellite system (GPS and/or GLONASS). The spectrogram shown in Figure 2 has been obtained by processing records of the induction magnetometer LEMI-30. Two horizontal or all three orthogonal components of ULF magnetic field oscillations are usually recorded. The magnetometer should be located far from industrial noise sources and contain a $50 \mathrm{~Hz}$ notch filter.

The IAR emission is visualized by constructing a spectrum of data from the output of the magnetometer. The most illustrative is the dynamic spectrum, but the time sequence of usual emission power spectra is more convenient to track amplitude variations. When constructing the dynamic spectrum, the most suitable values of the spectral window, overlaps, and other parameters are selected depending on the ADC sampling rate, which for successful display of all DSB parts must be at 
Obs. MONDY, 8 January 2019

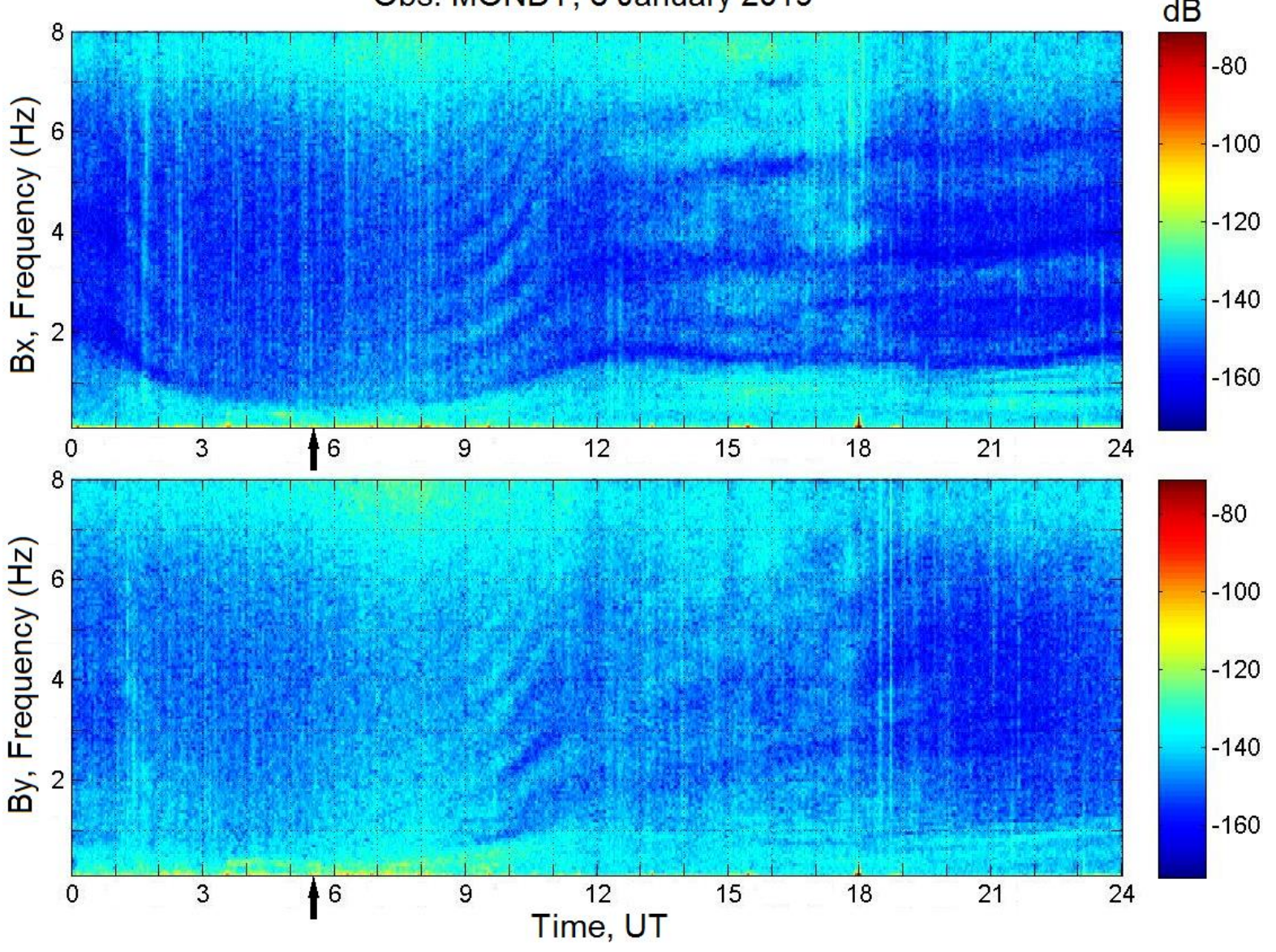

Figure 2. A daily spectrogram of the resonator emission. Two magnetic field components are given: meridional $B_{x}$ and azimuthal $B_{y}$. Color scales on the right allow us to relate colors on the dynamic spectrum to emission intensity in decibels. Arrows under the time axes indicate the local noon

least $32 \mathrm{~Hz}$; and ADC digit capacity, not less than 24. Daily emission spectrograms are constructed most often.

Further analysis is usually performed using visual methods: on a spectrogram with the cursor we measure frequencies of each DSB at certain intervals, compile tables that are compared with similar tables of other geophysical parameters, and conduct statistical and other types of analysis depending on objectives of the study.

\section{MORPHOLOGY OF IAR EMISSION}

\subsection{Emission characteristics}

As noted above, on a daily spectrogram the emission has the form of a set of fan-shaped DSB. Under various conditions there are from two-three to ten bands. The most pronounced of them are usually the second and third signal harmonics, i.e. the second and third bands from below; the first harmonic is often masked by noise of other low-frequency oscillations, whereas the top bands gradually merge with the background due to natural signal amplitude decay as the harmonic number increases.

The most striking feature of DSB behavior is their diurnal variation. The bands are downmost near the local noon, at the same time the spacing between the bands and their thickness are minimum. The maximum
DSB frequency always falls on the nighttime, but it is blurred and can be shifted in time by two-three hours. Thickness of the bands and distance between them (socalled frequency scale) at this time are maximum; sometimes, the bands are almost parallel to the time axis, but are often wave-shaped. The frequency scale and frequency of each of the harmonics may change during the day 2-3 times. So, at the mid-latitude observatory Mondy (for its coordinates see Table) at solar maximum the frequency scale from day to night increases, on the average, from $0.25-0.35$ to $0.72-0.9 \mathrm{~Hz}$; and at solar minimum, from $0.45-0.65$ to $1.0-1.5 \mathrm{~Hz}$. Figure 3 presents typical emission spectrograms for winter months of solar minimum and maximum.

The DSB amplitude also varies during the day, although its variations, unlike the diurnal frequency variation, are irregular. When the bands become faint or completely disappear, it is sometimes difficult to understand whether this is due to a decrease in the emission intensity or due to enhancement of the irregular background shielding the IAR emission. An unwanted bright signal is sometimes detected which due to the limited dynamic range of the entire imaging system obscures the DSB clearly visible before and completely disappearing on the spectrogram. However, in general, DSB are best seen at night. In winter, they can be observed 
Coordinates of the observatories and stations whose observations are mentioned in the review

\begin{tabular}{|l|c|c|c|c|c|c|}
\hline \multirow{2}{*}{\begin{tabular}{c}
\multirow{2}{*}{$\begin{array}{c}\text { Observatory } \\
\text { (station) }\end{array}$} \\
\cline { 2 - 5 }
\end{tabular}} & \multicolumn{2}{|c|}{\begin{tabular}{c} 
Geographic coordinates \\
\cline { 2 - 5 }
\end{tabular}} & \multicolumn{2}{c|}{$\begin{array}{c}\text { Corrected geomagnetic coor- } \\
\text { dinates }\end{array}$} & \multirow{2}{*}{$\begin{array}{c}L \text { parameter } \\
\text { of magnetic } \\
\text { shell }\end{array}$} & Epoch \\
\hline Istok & 70.0 & 88.0 & 6 & 163 & 6.09 & 2015 \\
\hline Kilpisjärvi & 69.0 & 20.9 & 66 & 105 & 6.01 & 1993 \\
\hline Sodankylä & 67.2 & 26.4 & 64 & 107 & 5.25 & 1997 \\
\hline Lehto & 64.7 & 33.9 & 61 & 112 & 4.25 & 2012 \\
\hline Gakona & 62.4 & 214.8 & 64 & 269 & 4.96 & 2006 \\
\hline Borok & 58.1 & 38.2 & 54 & 113 & 2.95 & 2000 \\
\hline Novaya Zhizn & 56.0 & 45.7 & 52 & 120 & 2.62 & 1985 \\
\hline Karymshina & 52.9 & 158.2 & 46 & 227 & 2.14 & 2001 \\
\hline Mondy & 51.6 & 100.9 & 47 & 175 & 2.21 & 2013 \\
\hline Ulaanbaatar & 47.9 & 106.8 & 43 & 181 & 1.93 & 2015 \\
\hline Crete & 35.2 & 25.2 & 28 & 97 & 1.31 & 1999 \\
\hline Muroto & 33.3 & 134.2 & 27 & 207 & 1.28 & 2015 \\
\hline Acad. Vernadsky & -65.7 & 295.7 & -51 & 9 & 2.57 & 2008 \\
\hline
\end{tabular}
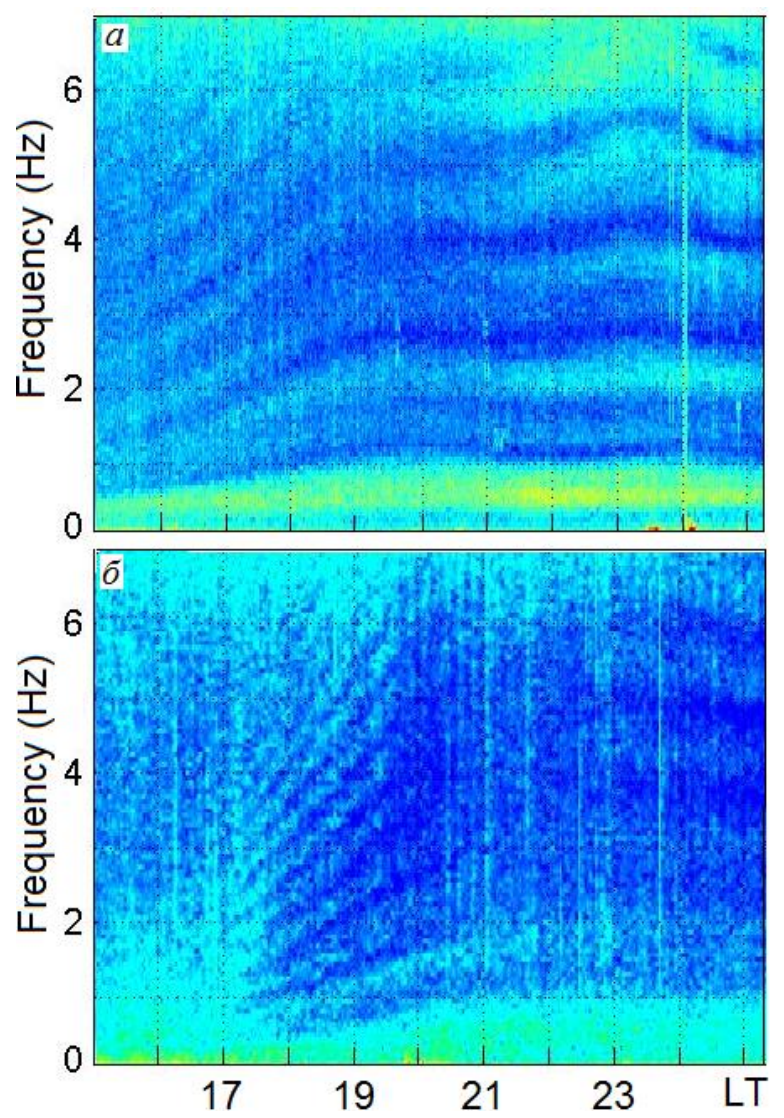

Figure 3. Typical spectrograms of the IAR emission observed by the Observatory Mondy in winter during solar minimum on December 26, $2009(a)$ and during solar maximum on February 11, $2012(b)$

day and night, whereas in summer they occur only for two-three hours a night.

These DSB features are quite understandable from the point of view of existing ideas about the nature of IAR and its emission. There are, however, some details that do not fit the standard model of the resonator. We will discuss them later, and here we just mention such particular anomalies in DSB as band splitting into smaller ones, their halving, merging, as well as differences in behavior between the bands in different emission components.

\subsection{IAR geography}

Geographic distribution of DSB observed is fairly wide. Table provides information on the location of the observatories and stations mentioned in this review. It lists geographic and corrected geomagnetic coordinates. The latter have been calculated for a point at a height of $100 \mathrm{~km}$ above the observing station for the epoch given in the last column. It corresponds to the middle of the observation period at this station. The $L$ parameter of the magnetic shell adjacent to the station is also given. We have used the algorithm from [https://omniweb. sci.gsfc.nasa.gov/vitmo/cgm.html].

The IAR emission was first detected at midlatitudes [Belyaev et al., 1987] at the station Novaya Zhizn, and later at many other mid-latitude stations — in Russia from Borok Geophysical Observatory [Dovbnya et al., 2019a] to the station Karymshina near PetropavlovskKamchatsky [Molchanov et al., 2004]. At high latitudes, IAR DSB were observed both in the Arctic at the station Kilpisjärvi [Belyaev et al., 1999], at Sodankylä Geophysical Observatory [Yahnin et al., 2003], at the station Gakona [Parent et al., 2010], at the station Istok near Norilsk [Potapov et al., 2017], and in Antarctica at the station Academic Vernadsky [Koloskov, Baru, 2012]. DSB were detected both at the low-latitude stations on island Crete [Bösinger et al., 2002] and at the station Muroto [Nosé et al., 2017]. A number of papers have compared DSB observations made at two or more stations [Demekhov et al., 2000; Pokhotelov, 2003; Koloskov, Baru, 2012; Potapov et al., 2017]. The most valuable results were obtained from simultaneous measurements with magnetometer chains. Potapov et al. [2017] have compared simultaneous observations of the IAR emission at the meridional chain of three stations in the range of geomagnetic latitudes from $43^{\circ}$ (Ulaanbaatar Observatory) to $66^{\circ}$ (station Istok). In [Nosé et al., 2017], magnetometers were located at low latitudes along the meridional chain $5.8^{\circ}$ long. The results important for the study of the IAR structure have been obtained in [Ivanov et al., 2017], where simultaneous observations of electric emission components at five stations are compared. The chain of stations, spaced 
$\sim 50 \mathrm{~km}$ apart, was extended along the meridian near the ionospheric trough.

At middle and high latitudes, the morphological properties of the IAR emission are virtually identical. At the same time, as evidenced by simultaneous observations at two mid-latitude stations and one high-latitude station [Potapov et al., 2017], the frequency mode at each of the stations reflects ionospheric conditions over it. Even at remote stations, frequency values can, however, be both close and vastly different on different days. At low latitudes, IAR emission properties have been studied by two groups of authors [Bösinger et al., 2002, 2004; Nosé et al., 2017]. They have found a number of properties that distinguish low-latitude DSB from mid- and high-latitude ones. It mainly concerns the frequency scale $\Delta f$ of the emission. At low latitudes, it can vary from characteristic for midlatitudes to much smaller values. We will discuss these features in more detail in the following sub-sections.

In general, the results of studies on the spatial distribution of IAR emission show that the ionospheric Alfvén resonator is a global permanent phenomenon, but characteristics of its emission are regional, depending on ionospheric conditions in a particular region. Special observations to measure the correlation radius of DSB characteristics and time variations have not yet been made. However, the available data, based on the findings obtained in [Potapov et al., 2017; Nosé et al., 2017], allows us to assess it as lying in the range 500 $1000 \mathrm{~km}$, which is comparable to the correlation radius $(\sim 1000 \mathrm{~km})$ providing a correlation coefficient of not less than 0.7 between $f_{\mathrm{o}} \mathrm{F} 2$ variations [Stanislawska et al., 1997].

\subsection{IAR emission dependence on solar cycle, season, and magnetic disturbance. Diurnal var- iation in probability of observing DSB}

Figure 4 presents histograms of the rate of DSB occurrence in 2010-2019 (except for 2015 when no observations were made). Magnetic measurements in the ULF band have been made at the mid-latitude observatory Mondy (for coordinates see Table 1), located in the Eastern Sayan Mountains near the border with Mongolia. The observation period substantially coincides with solar cycle 24 and includes 2467 days. During 2402 days (over $97 \%$ of the total number of days), there were at least short DSB intervals. The first histogram (Figure 4 , left) shows a cyclic variation in the probability of observing the IAR emission during solar cycle. The height of bars is proportional to the ratio of the number of days, whose daily spectrograms contain at least twohour intervals of DSB, to the total number of days for which there are observations for a given year. In general, it is clear that the absence of IAR emission is likely be an exception. Nonetheless, there is a certain cyclic variation. The maximum number of days without DSB was in 2014 - solar maximum in cycle 24 .

The second histogram (Figure 4, right) was constructed to illustrate the seasonal variation of the rate of DSB occurrence. On it, as on the first one, the height of bars indicates the relative number of days that contain at least two-hour intervals of DSB, not in years, but in months over the entire observation period. Like the cyclic variation, the rate of DSB occurrence also weakly depends on season. Yet in summer there are much more days without DSB traces, especially in June. This is due to the fact that in some summer days the level of homogeneous day noise background increases significantly [Dovbnya, et al., 2019b]. Its source is understudied; noteworthy is only one work on the nature of this phenomenon [Gokhberg, 1998].

Another factor influencing the probability of observing the IAR emission is considered to be magnetic activity [Yahnin et al., 2003; Molchanov et al., 2004]. However, provided that highly sensitive observation equipment is used [Potapov et al., 2014; Polyushkina et al., 2015], the magnetic activity dependence of the rate of DSB occurrence on daily spectrograms appears to be very weak. Most likely, major geomagnetic disturbances simply mask DSB, as noted in [Molchanov et al., 2004]. On the other hand, such disturbances by modifying ionospheric parameters can affect the resonator's frequency mode, as shown in [Parent et al., 2010; Semenova, Yahnin, 2014] and as discussed below.

Note that the aforementioned results, as well as those reported in [Potapov et al., 2014; Polyushkina et al., 2015], are very inconsistent with previously published findings [Belyaev et al., 1997; Yahnin et al., 2003; Molchanov et al., 2004]. The papers observed a significant dependence of the probability of DSB occurrence both on solar cycle phase and on season. At the same time, in terms of the seasonal dependence not of the probability of occurrence but of the duration of DSB observation during the day, the results obtained in [Potapov et al., 2014; Polyushkina et al., 2015] are fairly consistent with those of [Yahnin et al., 2003; Molchanov et al., 2004]. In all these papers, a strong seasonal variation in IAR emission duration with maximum in winter and minimum in summer was observed. These differences and, on the contrary, agreement between the results in different studies can easily be explained, in our opinion, by observation conditions and characteristics of measuring equipment in use. If observations were made with insufficiently sensitive magnetometers and/or in a noisy place, weak and short-term DSB parts were simply indistinguishable because of their small amplitude. This led to the apparent effect of the total absence of the emission in summer, especially during solar maximum, when natural noise generated by magnetic disturbances was added to artificial noise. During these periods, the signal/noise ratio decreased to minimum values. Highly sensitive equipment with proper filtering of low-frequency noise could detect the presence of DSB even under conditions of moderate disturbance at solar maximum; and only at very high disturbances the IAR emission bands were shielded by irregular noise. But when in the ionosphere there are conditions under which the energy of waves, trapped by the resonator, cannot penetrate to Earth (it happens in the daytime, away from the winter solstice), even sensitive magnetometers are helpless, and their results coincides with measurements of less sensitive instruments. 

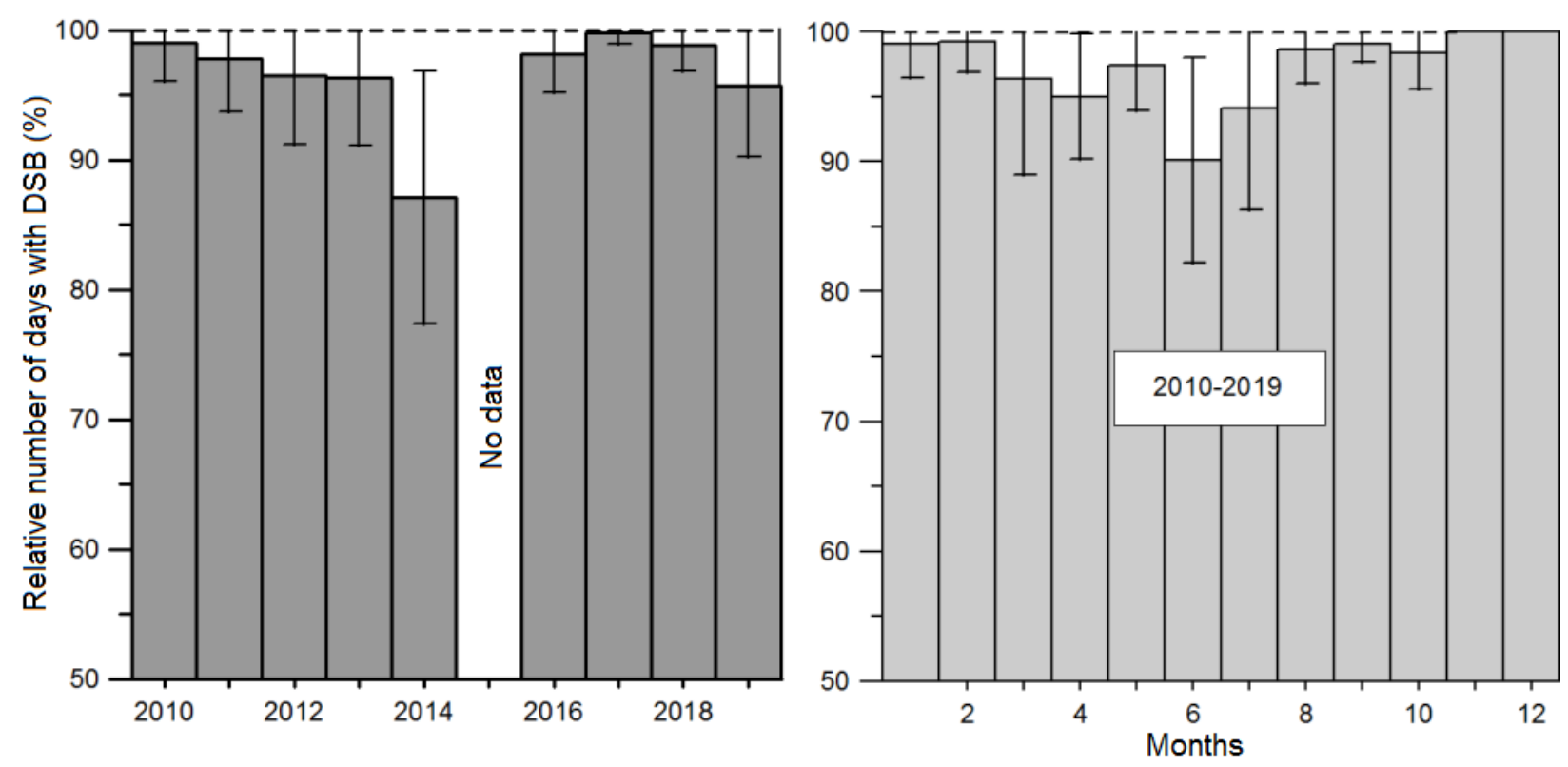

Figure 4. Histograms of the relative number of days during which the Observatory Mondy from 2010 to 2019 observed IAR DSB: depending on the year of observation (left); depending on the month of the year (right). Vertical lines indicate standard deviations

There are different points of view on the causes of the absence of the emission in summer daytime and at solar maximum. Belyaev et al. [1997] believe that during periods of high solar activity the resonator $\mathrm{Q}$ factor is reduced dramatically. Its cause is a smooth decrease in plasma density at the upper boundary of the resonator due to intense solar radiation and energetic particle fluxes. This blurs the Alfvén speed maximum therein. In the daytime in the lower layers of the ionosphere, wave absorption increases. Both boundaries lose their ability to efficiently reflect waves, and the resonant properties of the cavity disappear. A similar view is held by Nosé et al. [2017]. From observations at the low-latitude station Muroto, they have found a distinct diurnal variation in the probability of DSB occurrence with a plateau at night hours and early in the morning and with a sharp decrease at 05-06 LT. Seasonal variation at this station is rather uneven and has a diffuse peak from May to September. The authors attribute both the dependences to changes in the IAR Q factor and to variations in the generation source of waves, trapped by the resonator, global thunderstorm activity. We may probably agree with this explanation of seasonal variation. However, the cause of such a sharp diurnal variation in the rate of DSB occurrence can hardly be a change in the Q factor since according to the estimates made by the authors, it changes during the day by no more than $40 \%$. Molchanov et al. [2004] explain the absence of the emission in the summer daytime by the diurnal variation in another possible source — the E-layer neutral wind whose velocity is minimal in spring and early summer.

In papers [Potapov et al., 2014; Polyushkina et al., 2015], seasonal variations in DSB daily length were compared with the duration of shading of the $\mathrm{D}$ (height $H$ is $70 \mathrm{~km}), \mathrm{E}(H=110 \mathrm{~km})$, and $\mathrm{F} 2$ layers ( $H$ is taken to be equal to $200 \mathrm{~km}$ ) over the Observatory Mondy, where the observations were made. The comparison has shown that the DSB length is closest to the duration of night in the D layer. In the spring of 2011 and in the fall of 2010, the mean length of DSB coincides, on average, with the duration of night in this layer. However, in winter and spring IAR works for a few hours longer [Polyushkina et al., 2015]. The season-dependent change in the local time of the commencement of the emission is marked in Figure 5 (left) with filled circles; its end, with open circles. The top dashed line indicates the time of sunrise as a function of season at the height of the ionospheric D layer over the observatory; the bottom one, the time of sunset at the same height. We can see that the IAR emission is generally a night phenomenon; DSB are observed mostly when the lower ionosphere is shaded, but sometimes, especially in winter months, with a little elevation of the Sun above the horizon the emission begins and ends respectively before sunset and after sunrise, spanning 5-6 hrs of daylight. For the latitude of the Observatory Mondy, this ensures 24-hour observation of DSB in some days of December and January.

Thus, there is every reason to believe that the duration of shading of the lower ionosphere is the main factor affecting the duration of the IAR emission observed on Earth. This is confirmed by Figure 5 (right), which shows the dependence of the DSB length during the day on the duration of shading of the $\mathrm{D}$ layer. This result seems surprising because the resonator cavity does not cover the D layer. We can, however, assume that the presence of the D layer nevertheless somehow modifies the boundary condition at the bottom wall of the resonator, and the illumination of the layer affects reflection, propagation, and absorption of waves in the lower ionosphere. It nonetheless remains unclea to hold on the waves,r whether the illumination of the lower ionosphere leads only to a decrease in its transparency for Alfvén waves or to their complete absorption in the ionosphere. In the former case, IAR in the daytime continues 

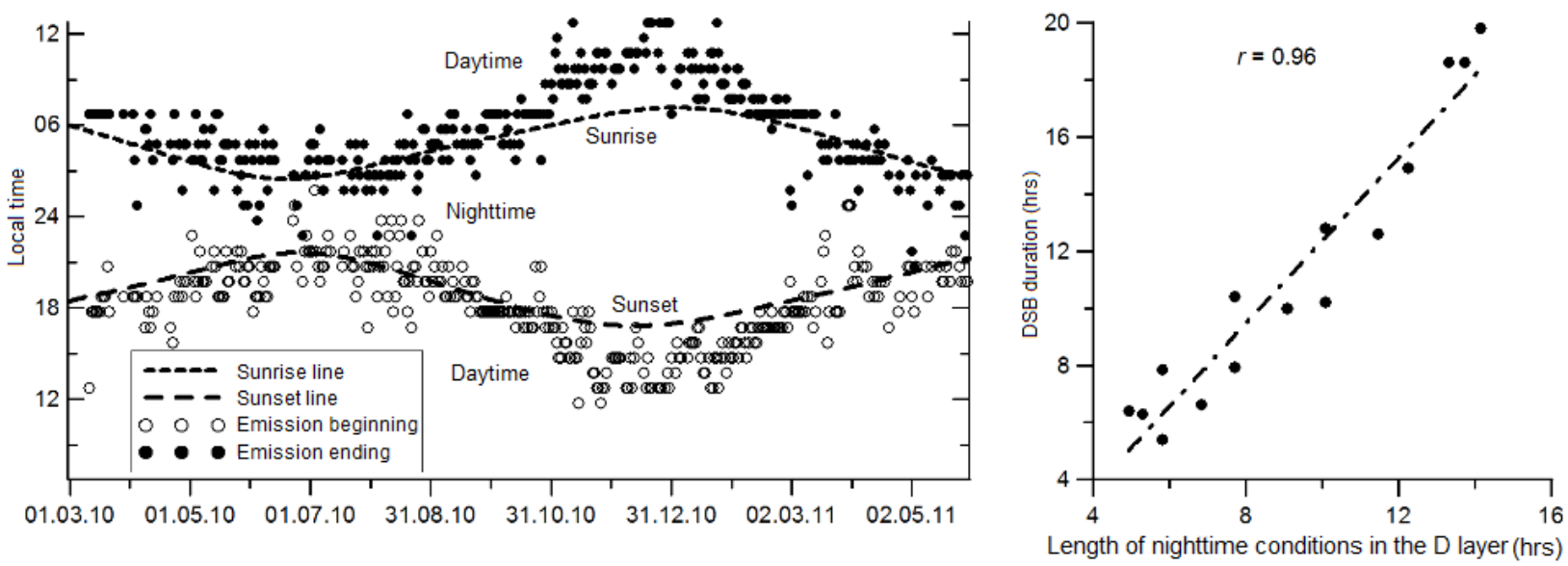

Figure 5. Seasonal variation in DSB length: change of the commencement (open circles) and end (filled circles) of the emission depending on season (left); DSB length dependence on the duration of night in the D layer (right) [Potapov et al., 2014]

which, however, cannot penetrate to Earth; in the latter, the wave activity in the resonator stops for a while. An answer to this question could be given by low-orbit satellite observations. The measurement data published to date is fragmentary and ambiguous [Zhao, Ni, 2006; Dudkin et al., 2014; Surkov, Pilipenko, 2016]. One possible explanation for the lack of reliable observations of IAR emission in the ionosphere is given in [Pilipenko et al., 2017]. Nonetheless, there is evidence of satellite observations of structures similar to DSB, although at night, but in the sunlit high-latitude ionosphere [Chaston et al., 2002], as well as during the day in the lowlatitude ionosphere [Simões et al., 2012]. In the second of these papers, the frequency range of spectral bands is much wider than that according to ground-based observations - from one to twenty or thirty hertz.

\subsection{Features of IAR emission spectrograms}

In most cases, IAR DSB are observed in both horizontal components. The vertical component is rarely used to study IAR, although there are traces of the emission there as well. Emission intensities in the meridional and azimuthal components may vary at different stations. For example, in Kamchatka the emission amplitude was much higher in the azimuthal component [Molchanov et al., 2004]; in the Observatory Mondy, the intensity of the bands is usually somewhat higher in the meridional component [Potapov et al., 2014]. This difference may be due to both the relative position of thunderstorm sources and the different nature of the underlying surface. At the same time, the brightness ratio between the bands can vary at one station from day to day or even within 24 hours (Figure 6,a). Furthermore, the behavior of the bands can vary quite considerably on spectrograms of different components - the number of bands can even mismatch (Figure 6, $b$ ). Quite often there are also other anomalies in the behavior of DSB: their merging, or vice versa, splitting and branching (Figure 6,c). In those cases when the frequency of the upper harmonics exceeds the fundamental frequency $(\sim 8 \mathrm{~Hz})$ of the Schumann resonator Earth-ionosphere, there are interesting effects of interaction between oscil- lations of the two resonators (Figure 6,d). All these features are difficult to explain with existing models, but some of them can be understood by taking into account the actual geometry of the magnetic field in the model of plane-layered ionosphere. For example, Ermakova et al. [2008] have made model calculations, taking into account inclination of geomagnetic field lines, which provided explanation of some anomalies in the DSB behavior: different frequency scale of the resonant structure in the meridional and azimuthal field components, the presence of several DSB frequency scales, and shift of the main frequency bands in one component relative to another.

Sometimes the DSB branching leads to the appearance of the fine structure of the emission in frequency: each band splits into several thinner ones (Figure 7; see also Figure 3 in [Ermakova et al., 2011]). In this case, the frequency scale of the fine structure bands is $3-5$ times smaller than the scale of the original structure. The fine structure was first detected at low latitudes (Crete) and was initially considered a feature of IAR spectra at these very latitudes [Bösinger et al., 2004]. Then, however, it was also found at midlatitudes: at the station Novaya Zhizn [Ermakova et al., 2011], at the observatories Borok and Mondy [Dovbnya et al., 2013a]. The IAR emission with a very small value of the frequency scale was also observed at Far-Eastern low latitudes - in Japan at the station Muroto [Nosé et al., 2017]. A typical difference in frequencies between adjacent harmonics therein at night and in decline of solar activity was $\sim 0.25 \mathrm{~Hz}$. Unlike Bösinger et al. [2004], Nosé et al. [2017] do not consider this value of the frequency scale of harmonics a feature of the fine structure. Indeed, at solar maximum even at midlatitudes in the daytime the frequency scale may be reduced to 0.25 $\mathrm{Hz}$. At the latitude of the station Muroto, as estimated by Nosé et al. [2017], regular values of the frequency scale may be even lower than $0.18 \mathrm{~Hz}$. At the same time, as seen in Figure 10, $a$ of the same paper, on other days of the observation period the frequency difference between adjacent harmonics could be much higher $(0.5$ $0.7 \mathrm{~Hz}$ ), equating to the frequency scale of the emission 

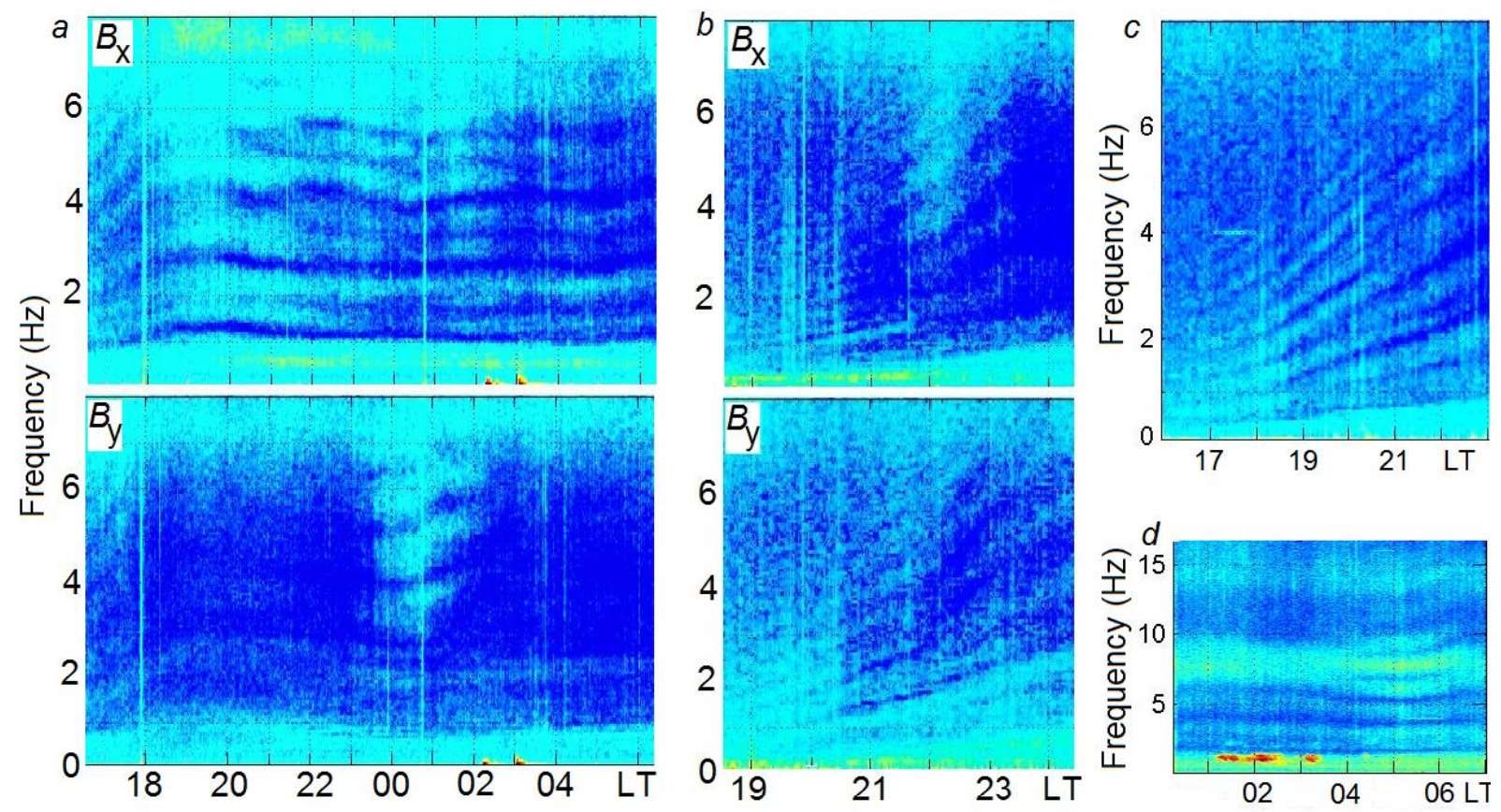

Figure 6. Examples of abnormal behavior of IAR DSB derived from observations at the Observatory Mondy: variation in the ratio of band intensities between components on December 21-22, $2009(a)$; different number of bands in two components according to observations on August 25, 2017 (b); merging and branching of bands on September 19, 2017 (c); interaction between IAR and Schumann resonator oscillations $(d)$

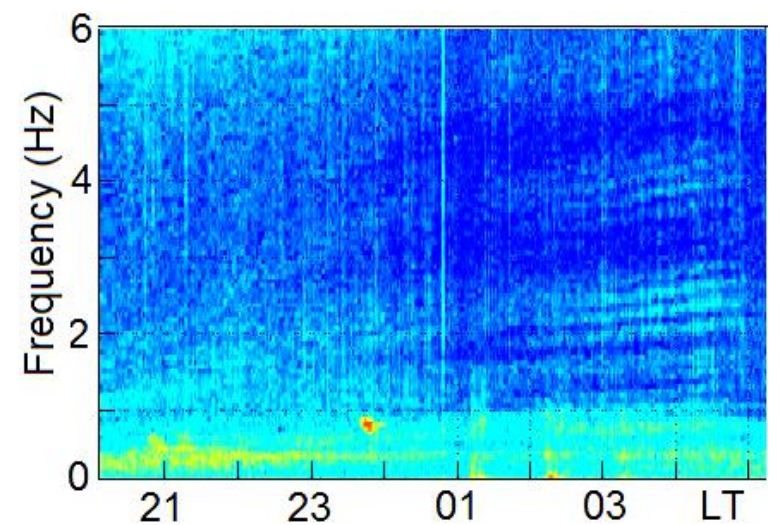

Figure 7. An example of DSB splitting with formation of a fine structure (Observatory Mondy, April 10-11, 2010)

at higher-latitude Japanese stations Nishiyama and Okura. Approximately the same picture is described in [Bösinger et al., 2004]. The bands spaced by $0.5 \mathrm{~Hz}$ apart and their fine structure with a scale of $\sim 0.12 \mathrm{~Hz}$ were observed almost simultaneously.

This may argue for the hypothesis put forward by Ermakova et al. [2011] about the role of a nonlocal ionosphere in the appearance of the fine structure: a signal may come from a remote region of the ionosphere with different parameters as compared to the local ones.

But in other cases, the additional structure appears not as a result of the splitting, but separately from the main pattern of the IAR emission, it is usually found under the upward lower band of primary emission, as shown in Figure 8 [Dovbnya et al., 2013b]. To explain this phenomenon, an assumption was made about the presence, along with the main resonator IAR, of an ad- ditional above-the-ionosphere resonator in which Alfvén waves are trapped at the vicinity of the geomagnetic field lines connecting the upper IAR boundary in the Northern Hemisphere with the upper IAR boundary in the Southern Hemisphere. Like IAR, the above-theionosphere resonator is open, so that the oscillation energy in it can seep into Earth, although it is entirely in the magnetosphere. The estimated eigenfrequencies of this resonator, obtained in [Dovbnya et al., 2013a], are consistent with observations. The characteristic frequencies are located between IAR frequencies and eigenfrequencies of MAR (magnetospheric Alfvén resonator) [Pilipenko, 2003] (field-line resonator [Hasegawa, Chen, 1974; Southwood, 1974]).

\section{POTENTIAL FOR DIAGNOSTICS OF THE IONOSPHERE}

Since the frequency of IAR emission bands and their frequency scale appeared to be directly related with ionospheric parameters, shortly after the detection of IAR it was proposed to use this relation for ground diagnostics of the ionosphere - its central region (F2 layer) [Yahnin et al., 2003; Koloskov, Baru, 2012; Fedorov et al., 2016c] and upper regions [Belyaev et al., 1990].

As for the F2 layer, there is extensive experimental evidence [Parent et al., 2010; Koloskov, Baru, 2012; Potapov et al., 2014, 2017; Potapov, Polyushkina, 2020a] of the close relationship of resonant frequencies and the IAR frequency scale with the critical frequency $f_{\mathrm{o}} \mathrm{F} 2$ of ionospheric radio sounding, and hence with the maximum electron density in this layer $N_{\mathrm{e}}=1.24 \cdot 10^{4}\left(f_{\mathrm{o}} \mathrm{F} 2\right)^{2}$, where $N_{\mathrm{e}}$ is measured in $\mathrm{cm}^{-3}$; and the critical frequency, 


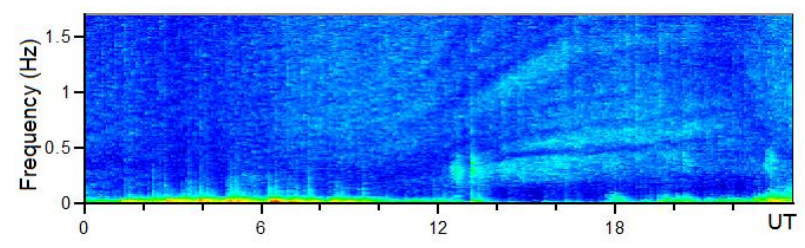

Figure 8. A dynamic spectrum of electromagnetic oscillations (Observatory Mondy, September 06, 2010), presumably excited in the above-the-ionosphere Alfvén resonator [Dovbnya et al., 2013b]

in MHz. Simplest IAR model (1) assumes that the fundamental frequency of the resonator is determined by the time of wave transit between the base of the ionosphere and the Alfvén velocity bending at a height 1-3 thousand kilometers. The main contribution is made by the time of passage through the wave path segment in which the Alfvén velocity $c_{\mathrm{A}}=B / \sqrt{4 \pi m_{\text {ieff }} N_{\mathrm{e}}}$ is minimal. This segment coincides with the maximum of the $N_{\mathrm{e}}$ vertical profile because the magnetic field $B$ and the effective ion mass $m_{\text {ieff }}$ change much slower than the abrupt change in ionization near its maximum.

Figure 9 shows the dependence of the DSB frequency scale $\Delta f$ on $N_{\mathrm{e}}$ in the F2-layer maximum, experimentally measured at the Observatory Mondy. The $N_{\mathrm{e}}$ values were calculated from measurements of $f_{0} \mathrm{~F} 2$, made by a digital ionosonde [Potapov et al., 2014]. The linear correlation coefficient between $\Delta f$ and $N_{\mathrm{e}}^{-1 / 2} r=0.88$ for the total volume of 99 measurements taken in different months over the period 2010-2011.

Potapov et al. [2017], using simultaneous mid- and high-latitude IAR emission observations, have analyzed in detail the correlation of diurnal variations in the inverse critical frequency $\left(f_{\mathrm{o}} \mathrm{F} 2\right)^{-1}$ of the ionosphere with variations in resonant frequencies $f_{i}$ and the IAR frequency scale $\Delta f$. The correlation coefficient in some cases was as high as 0.99 , not decreasing below 0.88 . This would allow us to accurately track diurnal variations

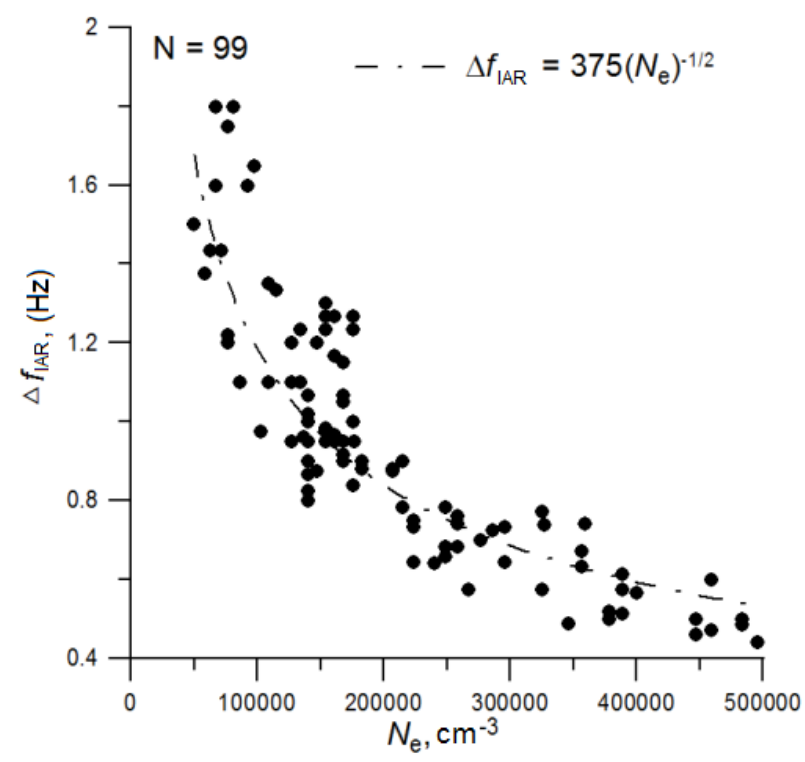

Figure 9. Relationship between the DSB frequency scale $\Delta f$ and the electron density $N_{\mathrm{e}}$ in the F2-layer maximum in the electron density at maximum ionospheric ionization through the simplest analysis of IAR emission spectrograms, i.e. by measuring frequencies $f_{i}$ of spectral bands or the distance $\Delta f$ between them. In reality, however, this is not yet possible because parameters of the relationship between $\left(f_{\mathrm{o}} \mathrm{F} 2\right)^{-1}$ and $f_{i}$, as well as $\Delta f$, vary considerably from day to day. For example, according to [Potapov et al., 2017], mean deviations of the slope coefficient of the linear regression between variations of these values may reach $36 \%$.

This suggests that the standard model of IAR proved to be insufficiently adequate for accurate explanation of the relationship between F2-layer critical frequency variations and measured spectral parameters of the IAR emission. Other, more complex, models, briefly reviewed above, do not solve the problem because they all are based on the scheme explaining the observed DSB by the action of the resonator. This just leads to the close relationship between $\Delta f$ and $f_{\mathrm{o}} \mathrm{F} 2$, but this scheme itself cannot explain the sudden changes in characteristics of this relationship. Changes in the frequencies observed may be caused by a change in the resonator geometry such as variations in the dipole structure [Lysak et al., 2013] or slope of geomagnetic field lines [Ermakova et al., 2008], but these factors do not change significantly from day to day or from hour to hour. Identifying possible causes of the abrupt changes in the regression coefficients of the relationship $\Delta f\left(f_{\text {cr }}\right)$ requires additional theoretical insights.

Potapov and Polyushkina [2020a] have adopted another method of estimating the electron density in the ionosphere from ground-based measurement without radio sounding, which sometimes, especially at high latitudes, does not yield results because of auroral disturbances. It is proposed to perform the multivariate regression analysis, involving, along with the IAR DSB frequency parameters, additional predictors such as magnetic and solar activity indices, local time, seasonal factor determining the duration of ionosphere shading on a given day, etc. Predictions of the critical frequency and minimum Alfvén velocity in the F2 layer, obtained by the ionospheric model IRI-2012 are also used. As a result, we can have a more accurate estimate of the electron density than that predicted by IRI-2012.

Certain advances have also been made in the use of measurements of DSB frequency parameters for diagnosing the upper ionosphere. Belyaev et al. [1990] pointed to the theoretical possibility of such diagnostics. A practical attempt to obtain information about parameters of the upper ionosphere with IAR was made only a quarter of a century later in [Potapov et al., 2016].

Measurements from the mid-latitude observatory Mondy and the high-latitude observatory Sodankylä were used. The authors solved the inverse problem of reconstructing vertical profiles of ions at heights from 2000 to $6000 \mathrm{~km}$ from the results of comparison between the IAR frequency scales measured from DSB spectrograms and calculated on the basis of IRI-2012, extrapolated to a height of $10000 \mathrm{~km}$. Unlike homogeneous model (1), used for F2-layer electron density di- 
agnostics, the authors considered continuous variations in magnetic field $B(l)$, effective ion mass $m_{\text {ieff }}(l)$, and electron density $N_{\mathrm{e}}(l)$, where $l$ is the distance along the longitudinal axis of the resonator. The frequency scale of the emission harmonics in this case has the form

$$
\Delta f=\left(\int_{l_{1}}^{l_{2}} \frac{\sqrt{4 \pi m_{\text {ieff }}(l) N_{\mathrm{e}}(l)}}{B(l)} d l\right)^{-1},
$$

where $l_{1}$ and $l_{2}$ is the position of the upper and lower walls of the resonator respectively. All the parameters were calculated to the height $l^{*}=2000 \mathrm{~km}$ with IRI-2012 and above $2000 \mathrm{~km}$ (to $10000 \mathrm{~km}$ ) with an interpolation formula similar to that applied in [Lysak, 2004],

$$
\begin{aligned}
& N_{\mathrm{i}}(l)=N_{\mathrm{O}^{+}} \mathrm{e}^{-b_{1}\left(l-l^{*}\right)}+N_{\mathrm{He}^{+}} \mathrm{e}^{-b_{2}\left(l-l^{*}\right)}+N_{\mathrm{N}^{+}} \mathrm{e}^{-b_{3}\left(l-l^{*}\right)}+ \\
& +N_{\mathrm{H}^{+}}\left(\frac{l^{*}+R_{\mathrm{E}}}{l+R_{\mathrm{E}}}\right)^{p} ; N_{\mathrm{e}}(l)=N_{\mathrm{i}}(l) ; \\
& m_{\mathrm{ieff}}(l)=\frac{1}{N_{\mathrm{e}}(l)} \times\left[16 N_{\mathrm{O}^{+}} \mathrm{e}^{-b_{1}\left(l-l^{*}\right)}+4 N_{\mathrm{He}^{+}} \mathrm{e}^{-b_{2}\left(l-l^{*}\right)}+\right. \\
& \left.+14 N_{\mathrm{N}^{+}} \mathrm{e}^{-b_{3}\left(l-l^{*}\right)}+N_{\mathrm{H}^{+}}\left(\frac{l_{*}+R_{\mathrm{E}}}{l+R_{\mathrm{E}}}\right)^{p}\right]
\end{aligned}
$$

here $N_{\mathrm{O}+}, N_{\mathrm{He}+}, N_{\mathrm{N}+}, N_{\mathrm{H}+}$ are concentrations of oxygen, helium, nitrogen, and hydrogen ions at the height $l^{*}=2000 \mathrm{~km}$ (according to IRI-2012); the power $p$ is fixed at $p=1 ; R_{\mathrm{E}}$ is the Earth radius $(6371 \mathrm{~km})$; $m$ ieff is measured in amu. Coefficients in the extrapolation formulas were selected so that to minimize the deviation of $\Delta f_{\text {calc }}$, calculated by Formula (3), from $\Delta f_{\text {meas }}$. For this purpose, the problem of searching for the minimum of function $\mathrm{F}\left(b_{1}, b_{2}, b_{3}\right)=\left|\Delta f_{\text {calc }}-\Delta f_{\text {meas }}\right|$ was solved numerically. The idea is that the coefficients thus optimized will yield vertical ion profiles that are the closest to the real ones. Of course, like any inverse problem, it can admit of ambiguous solutions. It is therefore necessary to impose additional conditions and limitations on the solutions selected. For example, such an additional requirement may be the condition of positive derivative of the function describing the profile of the relative proton density at the upper boundary of the region considered.

As a result, Potapov et al. [2016] obtained vertical profiles of the content and absolute concentration of oxygen, hydrogen, and helium ions; traced changes in the calculated profiles during the transition from daytime to nighttime (Figure 10). We can see, for example, that over the Observatory Mondy the relative content of oxygen ions at a height of over $2000 \mathrm{~km}$ at any time does not exceed $35 \%$, and decreases sharply with increasing height. At the same time, at high latitudes during the early evening hours it is reduced from more than $70 \%$ at $2000 \mathrm{~km}$ to $20 \%$ at $4000 \mathrm{~km}$, decreasing by night. Interestingly, the maximum content of oxygen ions is 2-4 times higher in Sodankylä than in Mondy. The time when this maximum is reached is shifted from $16 \mathrm{LT}$ in the auroral zone to $20 \mathrm{LT}$ in the mid-latitude observatory.

\section{INFLUENCE OF EXTERNAL FACTORS}

In one of the above sections, we have discussed the influence of seasonal and diurnal variations, as well as solar and magnetic activity on IAR emission. There are, however, other external factors that affect the IAR mode. One of them unexpectedly appeared to be the interplanetary magnetic field (IMF) vector direction. Guglielmi and Potapov [2017] have suggested that IAR is supplied with energy not only from below (thunderstorms, neutral winds, etc.), but also from above by electromagnetic waves from the magnetosphere and even from interplanetary medium. The above article presents the results of an indirect test of the proposed hypothesis.

Prerequisites are as follows. As is known, there is the so-called foreshock ahead of near-Earth shock wave front. It occupies an area bounded by the shock wave front and by the field line tangential to it. The foreshock is formed by the IMF field lines threading the front. Particles reflected from it move along these lines, exciting oscillations in a range from millihertz to several kilohertz, and are blown by the solar wind to the shock front. Some of them can penetrate further into the magnetosphere, and along geomagnetic field lines fall on the upper wall of IAR. In the meridional plane, the position of the foreshock relative to the equator depends on the relation between vertical $B_{z}$ and radial $B_{x}$ IMF components. If in the Sunmagnetosphere coordinate system the product of $B_{x} B_{z}>0$, the foreshock region is mainly above the equator; at $B_{x} B_{z}<0$, below it. Accordingly, we can assume that in the former case electromagnetic waves excited in the vicinity of the foreshock preferably penetrate into the Northern Hemisphere; in the latter, into the Southern Hemisphere. Using available observations of IAR activity at an observatory located in the Northern Hemisphere, we can experimentally check whether activity of IAR oscillations is really higher at $B_{x} B_{z}>0$ than at $B_{x} B_{z}<0$.

This hypothesis was tested using observational data on ULF oscillations from the Observatory Mondy over the period of March 01, 2010 to May 31, 2011 [Guglielmi, Potapov, 2017]. It was thought that on a given day the IAR emission was observed if on a daily spectrogram there was at least a five-hour interval of clearcut DSB (as opposed to the two-hour criterion adopted for construction of the distribution in Figure 5 of this review). Calculation has shown that the emission was observed for 297 days of the total number of days (457). Then, the estimated probability of occurrence of the emission $p=0.65$. Further IAR observations were compared with daily average IMF components $B_{x}$ and $B_{z}$, taken from the OMNIWEB database [https://omniweb. gsfc.nasa.gov/ow.html] for each day from March 01, 2010 to May 31, 2011. Given 28 days with zero $B_{x}$ or $B_{z}$ omitted, the final sample was 429 days. Cases of $B_{x} B_{z}>0$ and $B_{x} B_{z}<0$ is 194 and 235 days respectively. Thus, the probability of IAR occurrence $p_{1}=0.73$ when $B_{x} B_{z}>0$ and $p_{2}=0.59$ when $B_{x} B_{z}<0$. In terms of the size of the 

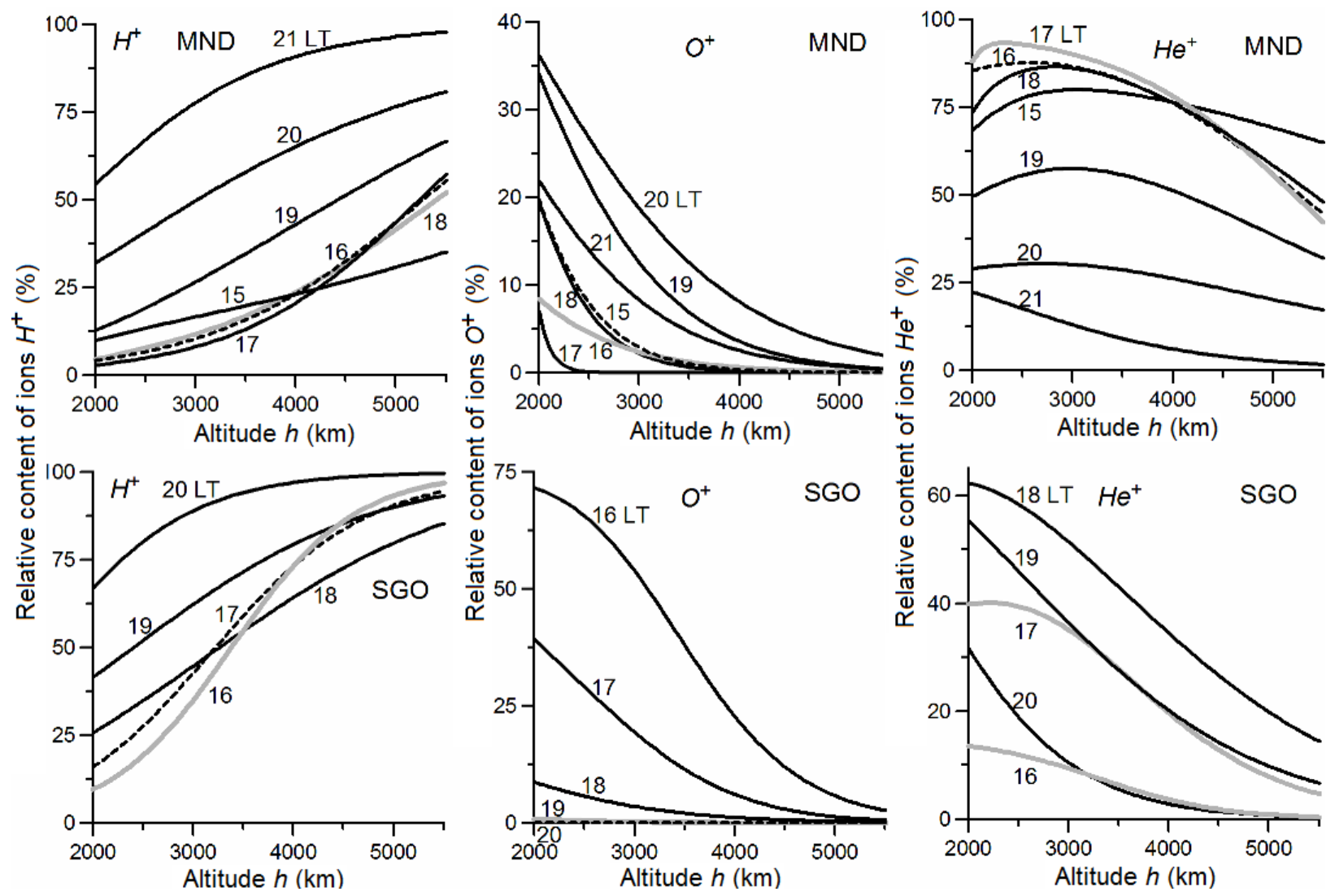

Figure 10. Estimated vertical profiles of relative content of hydrogen, oxygen, and helium ions over observatories Mondy (MND) and Sodankylä (SGO), obtained by analyzing IAR emission spectrograms [Potapov et al., 2016]

sample, the root-mean-square calculation error $p$ is $s=0.024$. Consequently, the difference between probabilities of observing the IAR emission in the Northern Hemisphere $\Delta p=p_{1}-p_{2}=0.14$ at northern $\left(p_{1}\right)$ and southern $\left(p_{2}\right)$ location of the foreshock is almost six times greater than the standard error; the three sigma rule is valid more than enough. The conclusion about the influence of IMF orientation on IAR activity should therefore be recognized as statistically significant. Of course, the difference between $p_{1}$ and $p_{2}$ is relatively small. This is most likely due to the fact that the extramagnetospheric sources that excite IAR act together with more powerful sources located in the atmosphere and lower ionosphere.

An alternative explanation is that the fluctuations that penetrate into the magnetosphere from outside do not supply energy for the ionospheric resonator, but serve only as triggers releasing free energy stored in the resonator, which is in a metastable state. There are some reasons for this explanation. For example, electromagnetic pulses of industrial origin from time to time affect IAR as a kind of triggers. Guglielmi et al. [2011] give examples of a sharp enhancement, and conversely a sudden disappearance of IAR emission at moments of the start of hour in the universal time (effect of hour marks - HM). It is clear that these HM themselves bear no relation to natural processes in the ambient medium. Nonetheless, they are a kind of clock signals synchronizing the work of technological systems around the world. The physical mechanisms of the impulse ac- tion of the technosphere on near-Earth space, responsible for the HM effect, are tentatively shown in [Samadani et al., 1981; Guglielmi, Zotov, 2007; Zotov, Guglielmi, 2010].

While statistically the magnetic disturbance has little effect on the rate of occurrence of IAR emission, in particular events, especially in auroral conditions, the sudden ionospheric disturbances associated with magnetospheric phenomena can significantly affect the frequency and amplitude IAR modes [Semenova, Yahnin, 2005, 2014; Semenova et al., 2008]. Parent et al. [2010] have carefully analyzed the February 28, 2006 event. They used simultaneous data from the induction magnetometer of the Observatory Gakona (see Table) and HAARP instruments located in close proximity - a digisonde, a riometer, and an all-sky camera. From $\sim 16$ LT, DSB on the magnetometer spectrogram behaved ordinarily, increasing in frequency in accordance with the evening decrease in the ionospheric critical frequency, measured by the digisonde. When a substorm began at $22 \mathrm{LT}$, DSB disappeared either because of suppression of resonant conditions by the substorm due to precipitation of particles or because of the spectrum of strong oscillations in the Pc1/Pi1B range. After the substorm, DSB appeared again, but harmonics shifted to lower frequencies with a concurrent decrease in the frequency scale. Calculations showed that this was due to the sharp increase in the F2-layer electron density, caused by substorm electron precipitation.

Other examples of the external influence on the IAR 
emission are cases when a relatively weak acoustic pulse from an earthquake brought about an abrupt change in the IAR excitation mode [Guglielmi et al., 2006]. In some cases, at the moment of arrival of seismic waves from an earthquake, the emission intensified, which was manifested in a sharp enhancement in DSB brightness; in other cases, the emission broke down and the harmonic structure of the bands disappeared [Potapov et al., 2008]. Grimalsky et al. [2010] have reported on such earthquake precursors as ionospheric disturbances, manifested in the occurrence of IAR emission. To explain causes of such effects of seismic activity to the mode of the ionospheric Alfvén resonator, the wellknown facts of the ionospheric response to processes of preparation of earthquakes and earthquakes themselves through acoustic, electromagnetic, electrostatic disturbances propagating upward from a seismic source are used (see [Potapov et al., 2008]).

\section{DISCUSSION}

We have described the results of the research into such an interesting geophysical object as the ionospheric Alfvén resonator, focusing mainly on morphological characteristics and their physical interpretation. Togeth$\mathrm{er}$, these results indicate that IAR is an independent structure of the magnetosphere-ionosphere system and plays an important role in the interaction between the two main parts of the system - the magnetosphere and the ionosphere. The IAR emission is a permanent global phenomenon whose characteristics determined by local ionospheric parameters depend on the local time and geographic location. As on the entire ionosphere, the external influence both from above (solar activity, particle precipitation from the magnetosphere) and from below (seismic activity, thunderstorms, neutral winds) is exerted on IAR. Some of these external actions serve as an energy source for resonant oscillations. The main sources are likely to be thunderstorm activity and winds in the upper atmosphere, but the electromagnetic emission flux from the magnetosphere and interplanetary medium may also make its own contribution.

The close relationship between IAR and ionospheric parameters defines the substantial potential of frequency resonator structure measurements both for ground-based diagnostics of the electron density in the ionospheric F2 layer and for the vertical profile of the ion composition above the ionosphere to a height of 4 to 6 thousand kilometers. We assume that like the total electron content that has become one of the main indices of the state of the ionosphere-magnetosphere system in recent decades, the IAR emission frequency scale $\Delta f$ will also be widely used in ionospheric research.

Of particular note is the clear-cut frequency and amplitude modulation of IAR emission. The frequency variation that appears on the spectrogram as a bright fan-shaped DSB structure is particularly impressive. In this review, we focused on amplitude variations of the emission. Potapov and Polyushkina [2020b] have discussed in detail the frequency modulation of three types: diurnal, seasonal, and solar-cyclic. The frequency and amplitude variations in the emission are driven by changes in local properties of the ionosphere. The main factors affecting the amplitude-frequency IAR mode is the electron density in the F2-region, which determines the harmonic frequency, the lower-ionosphere conductivity influencing the resonator $\mathrm{Q}$ factor and conditions of wave propagation to Earth's surface, and the vertical profile of electron and ion densities, which defines, together with the ionic composition, the Alfvén velocity profile along the axis of the resonator. As noted in [Guglielmi, Potapov, 2021], the IAR emission modulation has not a deep physical meaning. It is just that an observer, making diurnal rotation together with the adjacent local part of IAR, feels effect of diurnal variations in solar radiation on the state of the ionosphere. This may be superimposed by effects of solar activity variations and, in particular at high latitudes, by magnetic disturbances.

\section{CONCLUSION}

Here we focus on the still unsolved problems in the IAR research. As for the possibilities of practical application of information on the DSB frequency structure to ionospheric plasma diagnostics, the main problem is the absence of theoretical explanation of the interdiurnal jumps in numerical parameters of the relationship between emission characteristics and ionospheric conditions. If within 24 hours the relationship between the frequency scale $\Delta f$ of IAR emission and the electron density $N_{\mathrm{e}}$ in the ionospheric F2 layer remains steady and close, during the transition from one day to another parameters of this relationship may vary considerably; with the correlation between $\Delta f$ and $N_{\mathrm{e}}$ in the following days remaining high. It is necessary to determine what affects the relationship between $\Delta f$ and $N_{\mathrm{e}}$ in addition to the factors considered in the existing models.

We cannot so far regard as satisfactory the available explanations of the anomalies in DSB behavior: difference in the frequency structure between different emission components, merging or splitting of the bands. The question about the fine structure of the bands is also still unclear. There is a need for additional simultaneous measurements in several regions to confirm or reject the hypothesis about the nonlocal ionosphere to explain the fine structure.

There are few satellite measurements of IAR emission so far, especially those correlated with groundbased observations. Consistent observations in the ionosphere and on Earth could answer a number of questions about conditions of wave propagation to Earth's surface and their reflection from the lower boundary of the resonator; and could more accurately determine the position of this boundary. In particular, Potapov et al. [2021] have paid attention to the fact that the harmonic frequencies having an electric field node (and magnetic field antinode) beneath (Figure 1, left) form a sequence of odd numbers 1, 3, 5, 7 etc., and have suggested that only such modes can be observed on Earth. The harmonics with frequencies proportional to the positive integers 1, 2, 3, 4 (Figure 1, right) can only be observed in the ionosphere, they do not penetrate to Earth. This hypothesis can be tested by comparing DSB observations from the ground and from a satellite in the iono- 
sphere.

The work was financially supported by the Ministry of Science and Higher Education of the Russian Federation. The contribution of A.S. Potapov and T.N. Polyushkina was partially supported by RFBR grant No.19-05-00574. The work of B. Tsegmed was funded by grant SHUAG2017/17 from the Mongolian Academy of Sciences and by project SHUSS-2017/65 of the Ministry of Education, Science and Sport of Mongolia. The results were obtained using the equipment of Shared Equipment Center «Angara» [https://ckp-rf.ru/ckp/3056]. We are grateful to A.V. Guglielmi for his interest in work on this review. We are indebted to B.V. Dovbnya and B.I. Klain for helpful discussions.

\section{REFERENCES}

Baru N., Koloskov A., Yampolsky Y., Rakhmatulin R. Multipoint observations of ionospheric Alfvén resonance. Adv. Astron. Space Phys. 2016, vol. 6, no. 1, pp. 45-49. DOI: 10.17721/22271481.6.45-49.

Belyaev P.P., Polyakov S.V., Rapoport V.O., Trakhtengerts V.Yu. Finding resonance structure spectrum of the atmospheric electromagnetic noise background within shortperiod geomagnetic pulsation range. Doklady AN SSSR [Reports of AS USSR]. 1987, vol. 297, pp. 840-843. (In Russian).

Belyaev P.P., Polyakov S.V., Rapoport V.O., Trakhtengerts V.Y. Theory for the formation of resonance structure in the spectrum of atmospheric electromagnetic background noise in the range of short-period geomagnetic pulsations. Radiophys. Quantum Electron. 1989, vol. 32, no. 7, pp. 594-601.

Belyaev P.P., Polyakov S.V., Rapoport V.O., Trakhtengerts V.Yu. The ionospheric Alfvén resonator. J Atmos. Terr. Phys. 1990, vol. 52, no. 9, pp. 781-788.

Belyaev P.P., Polyakov S.V., Ermakova E.N., Isaev S.V. Experimental studies of the ionospheric Alfvén resonator using observations of the electromagnetic noise background over the solar cycle of 1985 to 1995. Radiophysics and Quantum Electronics. 1997, vol. 40, no. 10, pp. 1305-1319.

Belyaev P.P., Bösinger T., Isaev S.V., Kangas J. First evidence at high latitudes for the ionospheric Alfvén resonator. $J$. Geophys. Res. 1999, vol. 104, pp. 4305-4317. DOI: 10.1029/ 1998JA900062.

Bösinger T., Haldoupis C., Belyaev P.P., Yakunin M.N., Semenova N.V., Demekhov A.D., Angelopoulos V. Special properties of the ionospheric Alfvén resonator observed at a low-latitude station $(L=1.3)$. J. Geophys. Res. 2002, vol. 107, A10, pp. 1281-1289. DOI: 10.1029/2001JA005076.

Bösinger T., Demekhov A.G., Trakhtengerts V.Y. Fine structure in ionospheric Alfvèn resonator spectra observed at low latitude $(L=1.3)$. Geophys. Res. Lett. 2004, vol. 31, L18802. DOI: 10.1029/2004GL020777.

Chaston C.C., Bonnell J.W., Carlson C.W., Berthomier M., Peticolas L.M., Roth I., et al. Electron acceleration in the ionospheric Alfvén resonator. J. Geophys. Res. 2002, vol. 107, no. A11, p. 1413. DOI: 10.1029/2002JA009272.

Demekhov A.G., Belyaev P.P., Isaev S.V., Manninen J., Turunen T., Kangas J. Modelling the diurnal evolution of the resonance spectral structure of the atmospheric noise background in the Pc1 frequency range. J. Atmos. Solar-Terr. Phys. 2000, vol. 62, pp. 257-265. DOI: 10.1016/S13646826(99)00119-4.

Dovbnya B.V., Guglielmi A.V., Potapov A.S., Klain B.I. On the existence of an over-iospheric Alfvén resonator. Solnechno-zemnaya fizika [Solar-Terrestrial Physics], 2013a, iss. 22, pp. 12-15. (In Russian).

Dovbnya B.V., Guglielmi A.V., Potapov A.S., Rakhmatu- lin R.A. An additional resonator for ultra-low frequency waves. Geofizicheskie issledovaniya [Geophys. Res.]. 2013b, vol. 14, no. 2, pp. 49-58 (In Russian).

Dovbnya B.V., Klain B.I., Kurazhkovskaya N.A. Dynamics of ionospheric Alfvén resonances from the end of cycle 21 through cycle 24 of solar activity. Geomagnetism and Aeronomy, 2019a, vol. 59, no. 1, pp. 39-49. DOI: 10.1134/S00 16794019010061

Dovbnya B.V., Klain B.I., Kurazhkovskaya N.A. Influence of substorm activity on the formation of ultra low frequency noise emissions in the frequency range of $0-7 \mathrm{~Hz}$. Geomagnetism and Aeronomy, 2019b, vol. 59, no. 3, pp. 304311. DOI: 10.1134/S0016794019030076.

Dudkin D., Pilipenko V., Korepanov V., Klimov S., Holzworth R. Electric field signatures of the IAR and Schumann resonance in the upper ionosphere detected by Chibis-M microsatellite. J. Atmos. Solar-Terr. Phys. 2014, vol. 117, pp. 81-87. DOI: 10.1016/j.jastp.2014.05.013.

Ermakova E.N., Kotik D.S., Polyakov S.V. Studying specific features of the resonance structure of the background noise spectrum in the frequency range $1-10 \mathrm{~Hz}$ with allowance for the slope of the Earth's magnetic field. Radiophysics and Quantum Electronics. 2008, vol. 51, no. 7, pp. 575-584.

Ermakova E.N., Polyakov S.V., Semenova N.V. Study of the fine structure in the spectrum of low-frequency background noise at mid-latitudes. Physics of Auroral Phenomena. 2011, vol. 34, no.2, pp. 147-150.

Fedorov E., Mazur N., Pilipenko V., Engebretson M. Interaction of magnetospheric Alfvén waves with the ionosphere in the Pc1 frequency band. J. Geophys. Res.: Space Phys. 2016a, vol. 121, no. 1, pp. 321-337. DOI: 10.1002/2015JA021020.

Fedorov E., Mazur N., Pilipenko V., Baddeley L. Modeling the high-latitude ground response to the excitation of the ionospheric MHD modes by atmospheric electric discharge. $J$. Geophys. Res.: Space Phys. 2016b, vol. 121, iss. 11, pp. 11,282-11,301. DOI: 10.1002/2016JA023354.

Fedorov E., Mazur N., Pilipenko V., Ermakova E. Modeling diurnal variations of the IAR parameters. Acta Geodaetica et Geophysica. 2016c, vol. 51, no. 4, pp. 597-617. DOI: 10.1007/s40328-015-0158-9.

Gokhberg M.B. A new type of electromagnetic emission in the range of short-period geomagnetic oscillations. Doklady Earth Sciences. 1998, vol. 359A, vol. 3. pp. 423-424.

Grimalsky V., Kotsarenko A., Pulinets S., Koshevaya S., Perez-Enriquez R. On the modulation of intensity of Alfvén resonances before earthquakes: Observations and model. $J$. Atmos. Solar-Terr. Phys. 2010, vol. 72, no. 1, pp. 1-6. DOI: 10.1016/ j.jastp.2009.09.017.

Guglielmi A.V., Potapov A.S. Influence of the interplanetary magnetic field on ULF oscillations of the ionospheric resonator. Cosmic Res. 2017, vol. 55, no. 4, pp. 248-252. DOI: $10.1134 /$ S0010952517030042.

Guglielmi A.V., Potapov A.S. Frequency-modulated ULF waves in near-Earth space. Physics-Uspekhi. 2021, vol. 64, no. 5. DOI: $10.3367 /$ UFNe. 2020.06.038777.

Guglielmi A., Zotov O. The human impact on the Pc1 wave activity. J. Atmos. Solar-Terr. Phys. 2007, vol. 69, pp. $1753-1758$.

Guglielmi A., Potapov A., Tsegmed B., Hayakawa M., Dovbnya B. On the earthquake effects in the regime of ionospheric Alfven resonances. Physics and Chemistry of the Earth. 2006, vol. 31, pp. 469-472.

Guglielmi A.V., Dovbnya B.V., Potapov A.S., Hayakawa M. Effect of hour marks in activity of Pc1 electromagnetic oscillations as evidence of human impact on the ionosphere and magnetosphere. Solnechno-zemnaya fizika [Solar-Terr. Phys.]. 2011, iss. 19, pp. 88-92. (In Russian).

Guglielmi A.V., Klain B.I., Potapov A.S. Discrete spectrum of ULF oscillations of the ionosphere. 2021. arXiv: 
2105.01871 [physics.geo-ph].

Hasegawa A., Chen L. Theory of magnetic pulsations. Space Sci. Rev. 1974, vol. 16, no. 3, pp. 347-359. DOI: 10.1007/ BF00171563.

Hebden S.R., Robinson T.R., Wright D.M., Yeoman T., Raita T., Bösinger T. A quantitative analysis of the diurnal evolution of Ionospheric Alfvén resonator magnetic resonance features and calculation of changing IAR parameters. Ann. Geophys. 2005, vol. 23, pp. 1711-1721. DOI: 10.5194/angeo23-1711-2005.

Ivanov N.V., Tereshchenko E.D., Tereshchenko P.E., Kopytenko Y.A. Features of resonance structures in natural electromagnetic noise spectra in the region of the main ionospheric trough. Geomagnetism and Aeronomy. 2017, vol. 57, no. 6, pp. 752-760. DOI: 10.1134/S0016793217050097.

Koloskov A.V., Baru N.A. F-layer critical frequency determination from ionospheric Alfven resonance observations. Ukrainskii antarkticheskii zhurnal [Ukranian Antarctic J.]. 2011-2012, no. 10-11, pp. 114-120 (In Russian).

Lysak R.L. Feedback instability of the ionospheric resonant cavity. J. Geophys. Res. 1991, vol. 96, no. A2, pp. $1553-$ 1568. DOI: 10.1029/90JA02154.

Lysak R.L. Magnetosphere-ionosphere coupling by Alfvén waves at midlatitudes. J. Geophys. Res. 2004, vol. 109, A07201. DOI: 10.1029/2004JA010454.

Lysak R.L., Yoshikawa A. Resonant cavities and waveguides in the ionosphere and atmosphere. Magnetospheric ULF Waves: Synthesis and New Directions. Geophys. Monograph Ser. 2006, vol. 169, pp. 289-306. Washington: American Geophysical Union Publ., DC, USA, 2006.

Lysak R.L., Waters C.L., Sciffer M.D. Modeling of the ionospheric Alfvén resonator in dipolar geometry. J. Geophys. Res.: Space Phys. 2013, vol. 118, no. 4, pp. 1514-1528. DOI: 10.1002/jgra.50090.

Molchanov O.A., Schekotov A.Yu., Fedorov E., Hayakawa M. Ionospheric Alfvén resonance at middle latitudes: Results of observations at Kamchatka. Physics and Chemistry of the Earth. 2004, vol. 29, pp. 649-655. DOI: 10.1016/ j.pce.2003.09.022.

Nosé M., Uyeshima M., Kawai J., Hase H. Ionospheric Alfvén resonator observed at low-latitude ground station, Muroto. J. Geophys. Res.: Space Phys. 2017, vol. 122, pp. 7240-7255. DOI: 10.1002/2017JA024204.

Parent A., Mann I.R., Rae I.J. Effects of substorm dynamics on magnetic signatures of the ionospheric Alfvén resonator. J. Geophys. Res. 2010, vol. 115, iss. A2, CiteID A02312. DOI: 10.1029/2009JA014673.

Pilipenko V.A. Ultra-low-frequency waves in space and on Earth. In: Ocherki geofizicheskikh issledovanii: $k$ 75-letiyu Ob'edinennogo instituta fiziki Zemli im. O.Yu. Shmidta [Essays on Geophysical Research: to the 75th anniversary of the Schmidt Joint Institute of Physics of the Earth], Moscow: OIFZ RAN, 2003, pp. 216-228. (In Russian).

Pilipenko V., Dudkin D., Fedorov E., Korepanov V., Klimov S. IAR signatures in the ionosphere: Modeling and observations at the Chibis-M microsatellite. J. Atmos. SolarTerr. Phys. 2017, vol. 154, pp. 217-225. DOI: 10.1016/j.jastp.2015.12.012.

Pokhotelov O.A., Pokhotelov D., Streltsov A., Khruschev V., Parrot M. Dispersive ionospheric Alfvén resonator. J. Geophys. Res. 2000, vol. 105, no. A4, pp. 7737-7746. DOI: 10.1029/ 1999JA900480.

Pokhotelov O.A., Khruschev V., Parrot S., Senchenkov S., Pavlenko V.P. Ionospheric Alfvén resonator revisited: Feedback instability. J. Geophys. Res. 2001, vol. 106, no. A11, pp. 25813-258234. DOI: 10.1029/2000JA000450.

Pokhotelov O.A., Feygin F.Z., Khabazin Yu, Khruschev V.V., Bösinger T., Kangas J., Prikner K. Observa- tions of IAR spectral resonance at a large triangle of geophysical observatories.. Proc. XXVI Annual Seminar "Physics of Auroral Phenomena". Apatity: Kola, Science Center, RAS, 2003. pp. 123-126.

Polyakov S.V. On the properties of ionospheric Alfvén resonator. Simpozium KAPG po solnechno-zemnoi fizike (KAPG Simpozium on Solar-Terrestrial Physics), Book of Abstracts. Moscow, Nauka, 1976, Part 3, pp. 72-73.

Polyakov S.V., Rapoport V.O. Ionospheric Alfvén resonator. Geomagnetizm i aeronomiya [Geomagnetism and Aeronomy]. 1981, vol. 21, no. 5, pp. 816-822. (In Russian).

Polyushkina T.N., Dovbnya B.V., Potapov A.S., Tsegmed B., Rakhmatulin R.A. Frequency structure of spectral bands of the ionospheric Alfvén resonator and parameters of the ionosphere, Geofizicheskie issledovaniya [Geophysical Res.]. 2015, vol. 16, no. 2, pp. 39-57. (In Russian).

Potapov A.S., Polyushkina T.N. Estimation of the ionosphere critical frequency without radio sounding. IEEE Trans. Geoscience and Remote Sensing. 2020a, vol. 58, no. 7, pp. 5058-5065. DOI: 10.1109/TGRS.2020.2972011.

Potapov A.S., Polyushkina T.N. Response of IAR frequency scale to solar and geomagnetic activity in solar cycle 24. AIMS Geosciences. 2020b, vol. 6, no. 4, pp. 545-560. DOI: $10.3934 /$ geosci.2020031.

Potapov A.S., Dovbnya B.V., Tsegmed B. Earthquake impact on ionospheric Alfvén resonances. Izvestiya. Physics of the Solid Earth. 2008, no. 4, pp. 93-96. (In Russian).

Potapov A.S., Polyushkina T.N., Dovbnya B.V., Tsegmed B., Rakhmatulin R.A. Emissions of ionospheric Alfvén resonator and ionospheric conditions. J. Atmos. Solar Terr. Phys. 2014, vol. 119, pp. 91-101. DOI: 10.1016/j.jastp.2014.07.001.

Potapov A.S., Polyushkina T.N., Oinats A.V., Pashinin A.Yu., Raita T., Tsegmed B. First attempt to estimate the ion content over the ionosphere using data from the IAR frequency structure. Sovremennye problemy distantsionnogo zondirovaniya Zemli iz kosmosa [Current problems in remote sensing of the Earth from space]. 2016, vol. 13, no. 2, pp. 192-202. DOI: 10.21046/20707401-2016-13-2-192-202. (In Russian).

Potapov A.S., Polyushkina T.N., Tsegmed B., Oinats A.V., Pashinin A.Yu., Edemskiy I.K., et al. Considering the potential of IAR emissions for ionospheric sounding. J. Atmos. Solar-Terr. Phys. 2017, vol. 164, pp. 229-234. DOI: 10.1016/ j.jastp.2017.08.026.

Potapov A.S., Guglielmi A.V., Klain B.I. Discrete spectrum of ULF oscillations of the ionosphere. IEEE Trans. Geoscience and Remote Sensing. 2021. DOI: 10.1109/TGRS.2021.3092738.

Prikner K., Mursula K., Kangas J., Kerttula R., Feygin F.Z. An effect of the ionospheric Alfvén resonator on multiband Pc1 pulsations. Ann. Geophys. 2004, vol. 22, pp. 643-651. DOI: 10.5194/angeo-22-643-2004.

Samadani R., Fraser-Smith A.C., Villard Jr. O.G. Possible change in ntaural Pc1 pulsation activity caused by BART. $J$. Geophys. Res. 1981, vol. 86, pp. 9211-9214. DOI: 10.1029/ JA086iA11p09211.

Schekotov A., Pilipenko V., Shiokawa K., Fedorov E. ULF impulsive magnetic response at mid-latitudes to lightning activity. Earth, Planets and Space. 2011, vol. 63, pp. 119-128. DOI: 10.5047/eps.2010.12.009.

Sciffer M.D., Waters C.L. Propagation of ULF waves through the ionosphere: Analytic solutions for oblique magnetic fields. J. Geophys. Res. 2002, vol. 107, no. A10, p. 1297. DOI: 10.1029/2001JA000184.

Sciffer M.D., Waters C.L., Menk F.W. A numerical model to investigate the polarisation azimuth of ULF waves through an ionosphere with oblique magnetic fields. Ann. Geophys. 2005, vol. 23, p. 3457.

Semenova N.V., Yahnin A.G. Substorm effect on ground observations of signatures of the ionospheric Alfvén resonator. 
Proc. International Conference on Substorms-8, Univ. of Calgary, Banff, Canada, 2005.

Semenova N.V., Yahnin A.G. Sudden change in the resonance structure in the electromagnetic noise spectrum in the $0.1-10 \mathrm{~Hz}$ range during a substorm. Geomagnetism and Aeronomy. 2014, vol. 54, no. 3, pp. 316-322. DOI: 10.1134/S00 16793214030153.

Semenova N.V., Yahnin A.G., Vasil'ev A.N., Amm O. Specific features of resonance structures in spectra of ULF electromagnetic noise at high latitudes (Barentsburg Observatory). Geomagnetism and Aeronomy. 2008, vol. 48, pp. 36-44. DOI: $10.1007 / \mathrm{s} 11478-008-1005-8$.

Simões F., Klenzing J., Ivanov S., Pfaff R., Freudenreich H., Bilitza D., et al. Detection of ionospheric Alfvén resonator signatures in the equatorial ionosphere. J. Geophys. Res. 2012, vol. 117, A11305. DOI: 10.1029/2012JA017709.

Southwood D.J. Some features of field line resonances in the magnetosphere. Planet. Space Sci. 1974, vol. 22, no. 3, pp. 483-491. DOI: 10.1016/0032-0633(74)90078-6.

Stanislawska I., Juchnikowski G., Gulyaeva T. L. Correlation distances based on ionospheric and geomagnetic catalogues. Proc. STP-V Workshop. Hitachi, Japan, 1997, pp. 387390.

Surkov V.V., Pilipenko V.A. Spectral signatures of the ionospheric Alfvén resonator to be observed by low-Earth orbit satellite. J. Geophys.Res.: Space Phys. 2016, vol. 121, pp. 2783-2794. DOI: 10.1002/2015JA021912.

Surkov V.V., Pokhotelov O.A., Parrot M., Fedorov E.N., Hayakawa M. Excitation of the ionospheric resonance cavity by neutral winds at middle latitudes. Ann. Geophys. 2004, vol. 22, pp. 2877-2889. DOI: 10.5194/angeo-22-2877-2004.

Surkov V.V., Hayakawa M., Schekotov A.Y., Fedorov E.N., Molchanov O.A., Ionospheric Alfvén resonator excita- tion due to nearby thunderstorms. J. Geophys. Res. 2006, vol. 111, iss. A1, CiteID A01303. DOI: 10.1029/2005JA011320.

Trakhtengertz V.Yu., Feldstein A.Ya. Turbulent regime of magnetospheric convection. Geomagnetism and Aeronomy. 1987, vol. 27, pp. 221-228.

Trakhtengerts V.Yu., Feldstein A.Ya. Turbulent Alfvén boundary layer in the polar ionosphere. 1. Excitation conditions and energetic. J. Geophys. Res. 1991, vol. 96, no. A11, pp. 19363-19374.

Yahnin A.G., Semenova N.V., Ostapenko A.A., Kangas J., Manninen J., Turunen T. Morphology of the spectral resonance structure of the electromagnetic background noise in the range of $0.1-4 \mathrm{~Hz}$ at $L=5.2$. Ann. Geophys. 2003, vol. 21, pp. 779-786. DOI: 10.5194/angeo-21-779-2003.

Zhao Z.Y., Ni B.B. Signatures of the ionospheric Alfvén resonator from AUREOL-3 ULF/ELF fluctuation measurements. J. Atmos. Solar-Terr. Phys. 2006, vol. 68, pp. 191-201. DOI: $10.1016 /$ j.jastp.2005.10.009.

Zotov O.D., Guglielmi A.V. Diversity of geophysical manifestations of the ponderomotive forces. Proc. The $8^{\text {th }}$ International Conference "Problems of Geocosmo", St. Petersburg, Petrodvorets, 20-24 Sept. 2010, pp. 294-299.

URL: https://omniweb.sci.gsfc.nasa.gov/vitmo/cgm.html (accessed April 19, 2021).

URL: https://omniweb.gsfc.nasa.gov/ow.html (accessed April 19, 2021).

URL: http://ckp-rf.ru/ckp/3056 (accessed April 19, 2021).

How to cite this article

Potapov A.S., Polyushkina T.N., Tsegmed B. Morphology and diagnostic potential of the ionospheric Alfvén resonator. SolarTerrestrial Physics. 2021. Vol. 7. Iss. 3. P. 36-52. DOI: 10.12737/stp73202104. 